Review

\title{
Serenoa repens (Saw palmetto) for Lower Urinary Tract Symptoms (LUTS): The Evidence for Efficacy and Safety of Lipidosterolic Extracts. Part I
}

\author{
Stephen B. Strum (1)
}

check for updates

Citation: Strum, S.B. Serenoa repens (Saw palmetto) for Lower Urinary Tract Symptoms (LUTS): The Evidence for Efficacy and Safety of Lipidosterolic Extracts. Part I. Uro 2021, 1, 118-138. https://doi.org/ $10.3390 /$ uro1030015

Academic Editor: Mauro Gacci

Received: 2 July 2021

Accepted: 24 July 2021

Published: 28 July 2021

Publisher's Note: MDPI stays neutral with regard to jurisdictional claims in published maps and institutional affiliations.

Copyright: (C) 2021 by the author. Licensee MDPI, Basel, Switzerland. This article is an open access article distributed under the terms and conditions of the Creative Commons Attribution (CC BY) license (https:// creativecommons.org/licenses/by/ $4.0 /)$.
Community Practice of Hematology, Oncology and Internal Medicine, Focus on Prostate Cancer and Prostate Diseases, Nevada City, CA 95959, USA; sbstrum@gmail.com

\begin{abstract}
Lower urinary tract symptoms (LUTS) are classically characterized as being related to storage (e.g., frequency, urgency, and nocturia) or flow (e.g., weak stream, intermittency, straining, and incomplete emptying). Conventional prescription medications such as $\alpha 1$-blockers and $5 \alpha$-reductase inhibitors are used to treat progressive LUTS in men. Due to the adverse events associated with these prescription drugs, many patients with mild-to-moderate LUTS may decide to initiate treatment with non-prescription medications and/or dietary supplements. The lipidosterolic extract of Serenoa repens (LSESr), at a recommended daily dose of $320 \mathrm{mg}$ /day, has been the focus of numerous peer-reviewed studies and review articles concerning the treatment of LUTS, from the first publication in 1983 by Boccafoschi to the most recent publication in 2021 by Russo. Although it seems improbable that the beneficial effect of LSESr reflects a placebo effect given the consistent degree of efficacy comparing various studies published in different countries over a span of almost 40 years, this has been the prevailing impression stemming from essentially three publications in the Western medical literature. In addition, despite publications reporting findings of almost identical efficacy using LUTS endpoints such as the International Prostate Symptom Score (IPSS), the quality of life score (QoL), and the peak urinary flow (Qmax) in comparing LSESr with the $\alpha$-blocker tamsulosin or the $5 \alpha$-reductase inhibitor finasteride, and despite the recognized acceptance of the hexane lipidosterolic extract product (Permixon ${ }^{\circledR}$ ) as an herbal medicine in Europe showing value in the treatment of LUTS, the use of LSESr remains controversial in the US. Contributing to such an opposing view in the US are the wide variability in quality, composition, and dosage of Serenoa products, the commercial prevalence of dried berry powder supplements, and the lack of awareness of a standardized Serenoa phytotherapy lipidosterolic profile. Can the controversy over the efficacy of LSESr in the context of LUTS be resolved? By understanding the main literature that has led to clinical practice guidelines for Serenoa repens for LUTS in Europe and the US, and by an in-depth analysis of the totality of the clinical literature concerning dose, extraction method, and quality of the Serenoa product used, it should be possible to answer this question. Given the extent of this global analysis, this report is presented in three sections. Part I introduces LUTS. What are the demographics of LUTS? What symptoms are assessed by LUTS, and how do we quantify LUTS? Why would a non-prescription item be a valuable consideration in LUTS treatment versus other treatment options? What is basic information about Serenoa repens, and what defines a standardized LSESr product? What are the published trials that have affected the acceptability of Serenoa repens in the treatment of LUTS? Finally, a major portion of Part I discusses the four major reviews of Serenoa repens versus LUTS that have influenced how it is accepted in the USA, in Europe, and in other parts of the world. Part I, therefore, lays the groundwork and is foundational for the important findings relating to LUTS and Serenoa repens that will be presented as Parts II and III in subsequent review articles.
\end{abstract}

Keywords: lower urinary tract symptoms; LUTS; benign prostatic hyperplasia; BPH; saw palmetto; Serenoa repens; phytotherapy; lipidosterolic extract of Serenoa repens (LSESr); hexanic extract of Serenoa repens (HESr); ethanolic extract of Serenoa repens (EESr) 


\section{Introduction: LUTS, Symptom Scores, and Treatment Options}

The world population is growing. In 30 years, the population will have increased by $29 \%$, from the 2018 estimate of 7.6 billion to 9.9 billion in 2050 . With this population growth, the percentage of those who are age 65 and older is projected to increase from $9 \%$ to $16 \%$. In more developed countries, this increase in the elder population may reach $27 \%$, almost one of every three people! With this change in demographics, lower urinary tract symptoms (LUTS) will emerge as a top priority issue in healthcare and quality of life [1].

LUTS and benign prostatic hyperplasia (BPH) are commonly associated. BPH is a histological finding within the prostate gland found in $50 \%$ of men in their $50-60$ s and in nearly $90 \%$ of men over 80 years of age. However, only about $25 \%$ of men with BPH develop benign prostatic enlargement that causes obstruction and leads to LUTS. To confuse matters, sometimes small prostates are associated with LUTS and big prostates are not. The conclusion is that LUTS is multifactorial in its etiology and cannot simply be equated with prostate pathology [2]. In this report, I refer to "LUTS" as lower urinary tract symptoms in men that occur with or without documentation of BPH.

Quantifying LUTS is most commonly done using the International Prostate Symptom Score (IPSS) or the American Urological Association Symptom Index (AUA-SI) [3,4]. Both scoring systems include seven questions relating to urinary symptoms: (1) incomplete emptying; (2) frequency; (3) intermittency; (4) urgency; (5) weak stream; (6) straining, and; (7) nocturia. The IPSS has an additional question concerning the patient's quality of life, while the original AUA-SI did not. In short, LUTS is a collective term used to describe subjective urinary symptoms that typically affect (1) urine storage and (2) flow, with these two categories considered as subsets of the IPSS [5,6]. Storage symptoms can be remembered using the acronym FUN, for frequency, urgency, and nocturia. Storage symptoms are also referred to in many publications as "irritative" or "filling" symptoms. Flow symptoms can be remembered by the acronym WISE, for weak stream, intermittency, straining, and incomplete emptying. Flow symptoms have also been termed as "obstructive" or "voiding", but detailed urodynamic testing specifically designed for diagnosing outlet obstruction has failed to correlate obstructed from non-obstructed patients using the obstructive (also known as flow or voiding) subset score of the IPSS [7]. The terminology is confusing, with "storage", "filling", and "irritative" being synonymous, as are the descriptors "flow", "voiding", and "obstructive". Of key importance is that the storage (also known as filling, irritative) subset of the IPSS is associated with a 2-fold or greater effect on what bothers patients, compared with the voiding (flow, obstructive) subset. This "bother" is what significantly diminishes the QoL score [8]. In other words, the acronym "FUN" for frequency, urgency, and nocturia is ironically the opposite case in men with LUTS. This additional data input of the IPSS is termed the "bother question" or BQ and is sometimes designated as IPSS-BQ. Both the IPSS and the AUA-SI use the following to define the degree of LUTS: $1-7$ points = mild LUTS; 8-19 = moderate LUTS, and; 20-35 = severe LUTS.

Treatment options are needed for men when they may begin to experience mild-tomoderate LUTS. As symptoms intensify, conventional medications such as $\alpha_{1}$-blockers and $5 \alpha$-reductase inhibitors are routinely prescribed $[9,10]$. However, these drugs are often associated with adverse effects, such as dizziness, fatigue, and sexual dysfunction. In addition, the use of multiple drugs, also known as "polypharmacy", increases the risk of drug interactions, a still greater hazard for the elderly population affected by LUTS. Over 20 years ago, examining serious adverse drug reactions (ADRs) and drug-related fatalities in the US, Lazarou et al. reported over 2 million serious ADRs and over 100,000 drugrelated fatalities [11]. Since that publication in 1998, the number of new drugs in the US has increased by close to 1000 . With such high risks for pharmaceutical ADRs, many patients experiencing mild-to-moderate LUTS could significantly benefit by initiating treatment with medications and/or dietary supplements that have a minimal risk of ADRs, that lack significant drug interactions, and that are unassociated with sexual dysfunction and surely do not add to the risk of a drug-related fatality. Such agents would then fill an unmet need 
as an effective option for the management of mild-to-moderate LUTS and potentially as a means to halt the progression of LUTS/BPH that otherwise could eventually necessitate an invasive procedure. Clinicians should be aware of the clinical data involving the use of such supplements and understand which supplement(s) are efficacious during this early phase of LUTS. However, the value of supplements, and in particular phytotherapeutics such as LSESr, remains controversial, especially in the United States. In contrast, LSESr products are frequently used in Europe and other parts of the world to treat LUTS and require either a physician's prescription or more intensely regulated non-prescription products. In the United States, Serenoa-derived products are loosely marketed as "saw palmetto", and vary widely in quality, ingredients, and dosage. This situation is a consequence of such products being unregulated or scrutinized by any agency. This has muddied our ability to ascertain the efficacy and safety of Serenoa repens as a phytotherapeutic agent of value in the treatment of LUTS.

\section{The Basics about Serenoa repens}

The fruit (berries) of Serenoa repens contain 10\% to 15\% lipids. The extracted oil from ripe berries is rich in total fatty acids, free fatty acids, fatty acid esters, fatty alcohols, and sterols. The lipidosterolic extract of Serenoa repens (LSESr) is not pharmacologically equatable with crushed saw palmetto berry powder supplements that are sold in the United States and which have no established efficacy. The chemical profile for a quality LSESr with established clinical efficacy is published in the European Union (EU) monograph [12], and the lipid profile to validate saw palmetto extract identity has been developed by the US Pharmacopeia (USP) and requires a minimum of $80 \%$ total fatty acids, with specific fatty acid ratios [13]. The EU monograph for LSESr also established a minimum standard of $80 \%$ total fatty acids and additionally mandated the need to use a hexane extraction process. The requirements for free fatty acid content have not been addressed by either organization. The recommended dose of LSESr is $320 \mathrm{mg} /$ day, administered once daily or in two divided doses of $160 \mathrm{mg}$ [12].

Since the majority of OTC saw palmetto products vary widely in quality, composition, and dosage it is not surprising that the use of such non-standardized products along with variations in study design and patient populations has resulted in mixed clinical trial outcomes.

There have been two large US studies that showed no benefit of Serenoa repens (S. repens) compared with placebo. One used a supercritical carbon dioxide (the S. repens Treatment for Enlarged Prostates (STEP) trial in 2006 [14] and the other an ethanol extraction product of Serenoa repens (Complementary and Alternative Medicine for Urological Symptoms (CAMUS)) trial in 2011 [15]. These two negative studies represent a conundrum in assessing LSESr versus LUTS. In contrast, a standardized LSESr product, Permixon ${ }^{\circledR}$ (Pierre Fabre), obtained using hexane extraction, has been studied in at least 35 clinical trials between 1983 and 2015 and has been found to be effective for the treatment of LUTS [16-24]. A possible explanation for such differences in efficacy may relate to the impact of the extraction methodology and product quality. What is presented in this global review indicates that a standardized lipidosterolic extract is effective in the treatment of LUTS by improving urinary symptoms as measured by the IPSS, patient QoL, and peak urinary flow.

Because such a standardized profile is lacking for many Serenoa products, it is important to educate patients and physicians about selecting high-quality products that comply with recognized composition and dosage. Crucial questions about LSESr remain. Is there any difference in LSESr efficacy when a different extraction process is selected? Does the fatty acid content, free and/or total, play a significant role in efficacy? With all of these issues needing resolution, this investigation was undertaken to perform an in-depth analytical review of the entire body of peer-reviewed literature relating to the use of LSESr in the treatment of LUTS. The goals set forth were: 
(1) to critically evaluate the three major LSESr extraction techniques (hexane, ethanol, $\left.\mathrm{CO}_{2}\right)$ used in treating LUTS and present information foundational in reading the LUTS literature, (i.e., the European versus the American perspective of LSESr in LUTS treatment);

(2) to discuss LSESr side effects in short studies involving months and in long-term studies spanning years;

(3) to better understand the time to onset of action of LSESr;

(4) to ascertain the durability of efficacy;

(5) to investigate whether LSESr used in long-term studies can prevent the progression of LUTS and BPH; and,

(6) to conclude whether or not the effects of LSESr reflect a placebo effect.

Given the scope and depth of this global investigation, findings are presented in three parts. Part I discusses the foundational issues enumerated above as 1; Parts II and III, which will be presented in subsequent review articles, will present derivative results involving topics $2-4$, and 5-6, respectively.

\section{Perspectives on Serenoa repens Efficacy versus LUTS}

In the United States, several clinical studies investigating the efficacy of various LSESr products for the treatment of LUTS have had mixed results. Two large clinical trials failed to show a benefit for LSESr versus placebo and have led to a generally negative impression about using LSESr for LUTS [14,15]. Internationally, some reviews and meta-analyses failed to find consistency in the published literature concerning LSESr efficacy [25,26]. Four publications have been highly influential in the clinical acceptance of LSESr in LUTS therapy: the European Scientific Cooperative on Phytotherapy (ESCOP) 2003 monograph [27], the 2012 Cochrane meta-analysis [26], the 2014 European Medicines Agency (EMA) monograph [12], and the 2014 guidelines of the American Urology Association (AUAG) [28]. In these four documents, each cited reference was retrieved and reviewed by this author (SBS). Data extraction relating to IPSS, QoL, $\mathrm{Q}_{\max }$, and side effects from each publication and from non-English-language papers translated in full into English using Systrans, Google Translate, and Easy Translator was done by SBS.

Seven criteria were selected as being reasonable to ascertain if a study was evaluable to assess LSESr efficacy for LUTS. These criteria were: (1) $\geq 20$ patients at study end, (2) a study duration of $\geq 2$ months, (3) one or more available LUTS clinical endpoints, such as IPSS or AUA-SI, QoL index, maximum urinary flow $\left(\mathrm{Q}_{\max }\right)$, (4) evaluation of LSESr monotherapy studies, (5) a $320 \mathrm{mg}$ dose of $S$. repens given once daily or $160 \mathrm{mg}$ twice daily, (6) an identified extraction method for the Serenoa product such as ethanol, carbon dioxide or hexane, and therefore an LSESr, and (7) consistent and interpretable data. Detailed notes were taken during the reading of each citation to understand the relevance of the paper to the body of scientific literature and the conclusions made by the author(s).

\subsection{The European Scientific Cooperative on Phytotherapy (ESCOP 2003)}

The European Scientific Cooperative on Phytotherapy (ESCOP), referred to here as ESCOP 2003, published a monograph on Serenoa repens. This is a ten-page report, with four pages related to references [27]. Of the 93 references, 44 were basic science studies that were not relevant to the issue of LSESr efficacy, and four references could not be obtained. An additional 22 references involved short studies of less than 2 months duration or were patient cohorts of fewer than 20 patients. The remaining 23 studies that met evaluability criteria were analyzed for objective findings of IPSS, QoL, and $Q_{\max }$ reported in each paper, or that could be determined by (SBS) from the study findings. Only six studies presented data for all three parameters. Fifteen studies were published either before IPSS scoring or elected not to use IPSS. In these cases, a clinical assessment was made (SBS) on urinary symptom change from data reported in the cited paper. A summary of the clinical findings in the 23 evaluable studies from ESCOP 2003 is shown in Table 1. 
Table 1. Twenty-three studies cited in ESCOP 2003 met eligibility for LSESr efficacy.

\begin{tabular}{|c|c|c|c|c|c|c|c|c|c|c|c|}
\hline \multirow{2}{*}{$\begin{array}{l}\text { Senior } \\
\text { Author }\end{array}$} & \multirow{2}{*}{$\begin{array}{l}\text { Ref. } \\
\text { (\#) }\end{array}$} & \multirow[t]{2}{*}{ Year } & \multirow{2}{*}{$\begin{array}{c}\text { Extraction } \\
\text { Method }\end{array}$} & \multirow{2}{*}{$\begin{array}{c}\text { Serenoa } \\
\text { Patients } \\
\text { (\#) }{ }^{\mathrm{a}}\end{array}$} & \multirow{2}{*}{$\begin{array}{c}\text { Study } \\
\text { Duration } \\
\text { (mos) }\end{array}$} & \multicolumn{2}{|c|}{$\begin{array}{c}\text { IPSS or Symptom } \\
\text { Change }\end{array}$} & \multicolumn{2}{|c|}{ QoL } & \multicolumn{2}{|c|}{$\mathbf{Q}_{\max }$} \\
\hline & & & & & & $\Delta$ & $\%$ & $\Delta$ & $\%$ & $\Delta$ & $\%$ \\
\hline $\begin{array}{l}\text { Cirillo- } \\
\text { Marucco }\end{array}$ & [29] & 1983 & Hexane & 47 & 4 & & $56 \S$ & & & +4.55 & $50.4 \S$ \\
\hline Cukier $\psi$ & {$[30]$} & 1985 & Hexane & 73 & 2 & & $33.3 \S \S$ & & & & \\
\hline Pescatore & [31] & 1986 & Hexane & 30 & 3 & & & & & +2.5 & 26.9 \\
\hline Authie & [32] & 1987 & Hexane & 500 & 3 & & $78.1 *$ & & & & \\
\hline Ollé Carreras & [33] & 1987 & Hexane & 40 & 2 & & 67.5 㧊 & & & & \\
\hline Orfei & {$[34]$} & 1988 & Hexane & 30 & 3 & & $50.3^{\wedge}$ & -2.17 & & +0.03 & 0.2 \\
\hline Mattei $\psi$ & {$[35]$} & 1990 & $\mathrm{CO}_{2}$ & 20 & 3 & & $55.2^{\wedge}$ & & & & \\
\hline Dathe & [36] & 1991 & Hexane & 49 & 6 & & & & & +5.90 & 49 \\
\hline Fabricius $x x$ & [37] & 1993 & $\mathrm{CO}_{2}$ & 176 & 6 & & $\%$ and $59 \%$ & & & & \\
\hline Romics & [38] & 1993 & $\mathrm{CO}_{2}$ & 31 & 12 & & & & & +4.3 & 39.0 \\
\hline Vahlensieck & [39] & 1993 & $\mathrm{CO}_{2}$ & 1334 & 4 & & $46.7 \S \S \S$ & & & & \\
\hline Vahlensieck & [40] & 1993 & $\mathrm{CO}_{2}$ & 312 & 3 & & & & & +5.8 & 51.8 \\
\hline Braeckman & [41] & 1994 & $\mathrm{CO}_{2}$ & 305 & 3 & -6.6 & 34.7 & -1.54 & 41.6 & +2.41 & 26.4 \\
\hline Bach & [42] & 1996 & $\mathrm{CO}_{2}$ & 315 & 36 & & 73.0 & & & +6.1 & 45.5 \\
\hline Carraro & [17] & 1996 & Hexane & 467 & 6 & -5.8 & 37.0 & -1.38 & 38.0 & +2.7 & 25.0 \\
\hline Kondas & [43] & 1996 & Ethanol & 38 & 6 & & & & & +4.08 & 39.0 \\
\hline Braeckman & [44] & $1997 b$ & $\mathrm{CO}_{2}$ & 125 & 3 & & 64.0 & & & & 29.8 \\
\hline Braeckman & [45] & 1997a & $\mathrm{CO}_{2}$ & 67 & 12 & -10.2 & 60.0 & -1.5 & 41.7 & +2.6 & 23.8 \\
\hline Gerber & [46] & 1998 & Ethanol & 46 & 6 & -7.6 & 37.0 & & & -0.7 & -5.0 \\
\hline Derakhshani & [47] & 1997 & Ethanol & 1047 & 3 & -7.4 & 40.4 & -1.61 & 45.9 & +3.7 & 30.8 \\
\hline Eickenberg & [48] & 1997 & Ethanol & 6967 & 6 & -8.0 & 44.4 & -1.8 & 37.5 & +3.0 & 23.1 \\
\hline Redecker & [49] & 1998 & Ethanol & 50 & 3 & & $47.7^{\mu \wedge}$ & & & +3.4 & 24.0 \\
\hline Ziegler Ж Ж & [50] & 1998 & Ethanol & 109 & 3 & & 35.6 & & & +3.72 & 28.9 \\
\hline \multicolumn{4}{|c|}{ Average Changes for All Studies } & 530 & 6 & -5.3 & $25 \%$ & -1.7 & $40 \%$ & +3.4 & $27 \%$ \\
\hline
\end{tabular}

Note: Clinical assessment of the change in IPSS, QoL, and $\mathrm{Q}_{\max }$ presented in the referenced paper, or as determined by SBS. ${ }^{\text {a Number of }}$ patients at study end or as reported. $\psi$ Placebo-controlled study. * Study prior to IPSS; nocturia, frequency, and urgency improvements of $82 \%, 67 \%$, and $85.3 \%$, respectively (average improvement $78.1 \%$ ); average complete resolution of these symptoms was $43.5 \%$. $§$ Study done prior to IPSS; raw data on nocturia; study also included $Q_{\max }$ results. $\S \S$ Study done prior to IPSS; raw data on nocturia. $\S \S \S$ IPSS not used. Number shown based on change in frequency and nocturia (urinations) pre- versus post-S. repens. ^ Using scores from frequency, nocturia, and incomplete emptying. ^ Using scores from frequency, nocturia, urgency, weak stream, and straining at beginning and end of study.

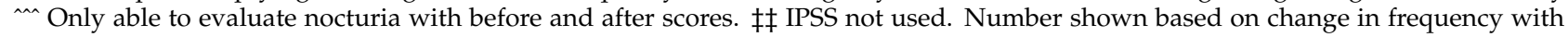
complete resolution in 27/40 patients. xx Fabricius's study did not use IPSS and reported on frequency and nocturia (39\% decrease in frequency and 59\% decrease in nocturia). Maximum average nocturia events dropped from 10 to 3. XK X Ziegler did not use IPSS, so his reported symptoms were based on percentage improvement involving weak stream, hesitancy, incomplete emptying, frequency, and nocturia. $\Delta$, mean change; -, negative change; \#, number; $\%$, percentage change; +, positive change; $\mathrm{CO}_{2}$, carbon dioxide; IPSS, International Prostate Symptom Score; mos, months; QoL, quality of life; $\mathrm{Q}_{\max }$, peak urinary flow (mL/s); Ref., reference citation.

A thorough investigation of the fifteen reports that assessed LUTS but did not use the IPSS revealed significant findings often not referred to in other publications. CirilloMarucco, et al. presented raw data on nocturia (56\% improvement), and their study also assessed $\mathrm{Q}_{\max }(+4.55 \mathrm{~mL} / \mathrm{s}, 50 \%$ improvement) [29]. Cukier presented raw data on nocturia from a placebo-controlled trial, which related to a 33\% clinical improvement [30]. Pescatore evaluated urinary flow and post-void volume. After 90 days, $\mathrm{Q}_{\max }$ improved by $27 \%(+2.5 \mathrm{~mL} / \mathrm{s})$ [31]. Authie reported improvements in nocturia, frequency, and urgency by $82 \%, 67 \%$, and $85 \%$, respectively [32]. The Ollé Carreras study reported changes in frequency symptomatology with complete resolution in $67.5 \%(27 / 40)$ of patients [33]. The calculated values (SBS) from the study data for IPSS, QoL, and $\mathrm{Q}_{\max }$, reporting a $50.3 \%$ change for IPSS, a -2.17 improvement in QoL, and a $+0.03 \mathrm{~mL} / \mathrm{s}(0.2 \%$ change $)$ in $Q_{\max }$, are presented in Table 1. Clinical data from Orfei were determined from reported scores for frequency, nocturia, urgency, weak stream, and straining at the beginning and end 
of the study [34]. Mattei's placebo-controlled trial with Serenoa repens presented clinical outcomes for frequency, nocturia, and incomplete emptying [35]. A 55\% improvement in symptom score was calculated from the study data (SBS). Dathe [36] and Romics [38] both reported improvements in urine flow $\left(\mathrm{Q}_{\max }+5.9 \mathrm{~mL} / \mathrm{s}, 49 \%\right.$ improvement and $+4.3 \mathrm{~mL} / \mathrm{s}$, $39 \%$ improvement, respectively). Fabricius did not use IPSS but reported a 39\% decrease in frequency and a $58 \%$ decrease in nocturia. In his study, the maximum average nocturia events dropped from 10 to 3 [37]. Vahlensieck published two papers in 1993 in ESCOP 2003. For the 1334-patient study, the data reflect changes in frequency and nocturia before and after Serenoa repens therapy [39]. In this large study, IPSS was calculated and indicated an improvement of $46 \%$ (SBS). The second Vahlensieck study evaluated 312 patients and used a 4-point scale to assess flow and post-void volume [40]. The use of Serenoa repens led to a $Q_{\max }$ improvement of $+5.8 \mathrm{~mL} / \mathrm{s}(51 \%)$. Kondas et al. only reported data on urinary flow $\left(\mathrm{Q}_{\max }+4.08,39 \%\right)$ [43]. For Redecker, multiple graphs within the publication were analyzed (SBS) to objectify the clinical endpoints of nocturia and peak urinary flow, with the finding of a $47.7 \%$ decrease in nocturia and an improvement in peak urinary flow by $+3.4 \mathrm{~mL} / \mathrm{s}$ ( $24 \%$ improvement). Figure 1 is adapted from Redecker and Funk's publication in German [49].

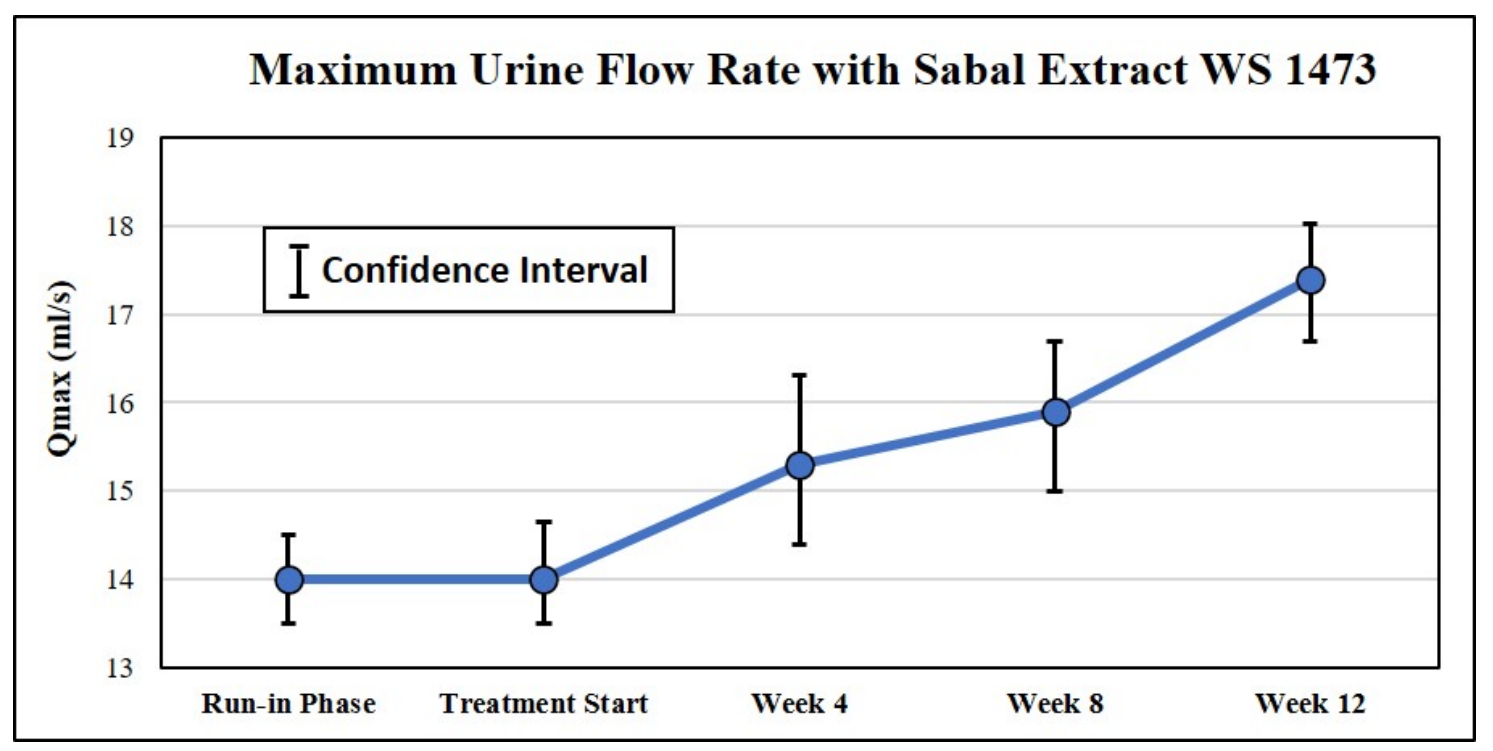

Figure 1. Data on maximum urine flow rate with the ethanolic extract of Serenoa repens (EESr) WS 1473 (Prostagutt Uno ${ }^{\circledR}$ ) over a 12 wk study. Peak urinary flow rate $\left(Q_{\max }, \mathrm{mL} / \mathrm{s}\right)$ mean value curve with a $95 \%$ confidence interval reported. Modified based on Redecker et al. [49].

Ziegler used a visual analog scale instead of the IPSS to record changes concerning weakness of the urinary stream, hesitancy, incomplete emptying, frequency, and nocturia. Improvements ranged from $20 \%$ to $50 \%$, with an overall improvement of $35.6 \%$. Peak urinary flow data assessment (SBS) showed an improvement of $28.9 \%$, with a change from a baseline value of 12.83 to $16.56(+3.73) \mathrm{mL} / \mathrm{s}$ by week 12 [50]. The IPSS data from the remaining eight citations considered by ESCOP 2003 are detailed in Table 1 . As per the last row of this table, the mean values of the 23 evaluable ESCOP studies for IPSS, QoL, and $\mathrm{Q}_{\max }$ were -5.3 points ( $25 \%$ improvement), -1.7 ( $40 \%$ improvement), $+3.4 \mathrm{~mL} / \mathrm{s}$ ( $27 \%$ improvement), respectively. No differences in the results were related to hexane, ethanol, or carbon dioxide extraction methodology. The mean patient numbers and study duration (months) were 530 and 6, respectively. Clinically, there was clear efficacy of LSESr in LUTS in the evaluable citations considered by ESCOP 2003. Surprisingly, this was not the official position taken by the ESCOP authors. My conclusion is that ESCOP 2003 authors did not perform a detailed assessment of evaluable studies. 


\subsection{The Cochrane Meta-Analysis (Cochrane 2012)}

The first Cochrane meta-analysis of $S$. repens was published in 2000 [51], updated in 2002 [52] and 2009 [53], and last revised in 2012 [26]. Cochrane 2012 included 32 randomized controlled trials and listed a total of 36 primary references that were considered conclusive as to the efficacy and toxicity of LSESr versus LUTS. There were 3 distinct studies by Braeckman that were referenced, but Braeckman 1994, a multicenter open study [41], and Braeckman 1997, a dosing regimen study [45], were not counted in the 32 controlled trials considered in Cochrane 2012. Additionally, Debruyne 2002 [19], a one-year randomized trial was included, but not the Debruyne 2004 subset analysis [18], despite the latter relating important independent findings on patient outcome. Finally, two papers by Sökeland from 1997 and 2000 are listed references, although only Sökeland 1997 [54] is considered in Cochrane 2012. The Sökeland 2000 publication is the same cohort as the 1997 publication with a subset analysis of prostate volume and therapeutic outcome [55]. The authors of the 87-page Cochrane 2012 review concluded that Serenoa repens did not improve urinary flow measures or prostate size versus placebo in men with LUTS/BPH $[25,26]$.

To assess the validity of the conclusions of Cochrane 2012, an independent analysis and review of all 36 studies [26] referenced were undertaken (SBS). The Sökeland 2000 paper on prostate volume was excluded because it was not relevant. Of the remaining 35 citations, LUTS efficacy was determined using the previously mentioned criteria for evaluability: $\geq 20$ patients at study end, study duration of $\geq 2$ months, a standardized $320 \mathrm{mg}$ dose of Serenoa repens, and LSESr monotherapy only. A flow chart to analyze the Cochrane 2012 citations is presented in Figure 2.

\section{Cochrane 2012 Meta-Analysis Studies (35 Relevant Citations)}



Figure 2. Cochrane 2012 patient evaluability. Of the 35 citations, only 15 were evaluable. Of those 15, only 3 were negative studies. * Some studies failed to meet evaluable criteria for more than one reason. Low patient numbers were identified in five studies, and a study duration of fewer than two months was found in six studies. Non-standard doses of Serenoa repens were noted in three studies, and nine studies did not involve monotherapy. In two studies, the intervention product and/or extraction technology could not be determined. Finally, one study had data that were not interpretable, and another article (Mohanty) did not specify the extraction technology.

In Figure 2, when applying the established evaluability criteria to Cochrane 2012, 20 of the $35(57 \%)$ were excluded as non-evaluable for LUTS efficacy. In five studies, the number of patients evaluated was less than 20. In six studies, the study duration was less than 2 months. In two citations, the dose of Serenoa was either unspecified or was less than $320 \mathrm{mg} /$ day. A combination of Serenoa with other phytonutrients, vitamins, or prescription drugs occurred in 9 studies, and the intervention product was not identified in 2 further studies for a total of 11 non-evaluable citations. The study by Mohanty [56], a 73-patient placebo-controlled study, used an LSESr product and fulfilled all the evaluability criteria with the exception that it did not specify the extraction method. It did show significant 
benefit for the LSESr arm but, lacking all required acceptability issues, it had to be moved to the non-evaluable group. The Reece Smith study [57] had data inconsistencies that made the interpretation of efficacy questionable. For the 15 studies meeting requirements for evaluability, detailed notes for each citation on endpoints such as IPSS, QoL, and Qmax were created (SBS), as shown in Table 2.

Table 2. Evaluable studies in Cochrane 2012. Of the 15 out of 35 studies considered evaluable, only 3 (shaded in gray) presented negative findings of LSESr efficacy. Patient numbers were active patients at study end.

\begin{tabular}{|c|c|c|c|c|c|c|}
\hline Senior Author & $\begin{array}{l}\text { Ref. } \\
{[\#]}\end{array}$ & Year & $\begin{array}{l}\text { Serenoa } \\
\text { Therapy }\end{array}$ & $\begin{array}{l}\text { Serenoa } \\
\text { Patients } \\
(\#)^{\mathrm{a}}\end{array}$ & $\begin{array}{c}\text { Study } \\
\text { Duration } \\
\text { (mos) }\end{array}$ & Comments on Study Data \\
\hline Cukier & {$[30]$} & 1985 & $\begin{array}{l}\text { Permixon } \\
\text { Hexane }\end{array}$ & 73 & 2 & $\begin{array}{l}\text { Frequency and nocturia significantly improved } \\
\text { with Permixon }\end{array}$ \\
\hline Pannunzio & {$[58]$} & 1986 & $\begin{array}{l}\text { Permixon } \\
\text { Hexane }\end{array}$ & 30 & 2 & $\begin{array}{l}\text { Permixon vs. gestonorone; } \mathrm{Q}_{\max } \uparrow+5.1(74 \%) \text { vs. } \\
\quad+2.2(28 \%) ; \text { no IPSS or QoL data }\end{array}$ \\
\hline Mattei & [35] & 1990 & $\begin{array}{l}\text { Talso } \\
\mathrm{CO}_{2}\end{array}$ & 20 & 3 & $\begin{array}{c}\text { Frequency } 43.8 \% \text { improved vs. } 7.1 \% \text { for placebo; } \\
\text { nocturia } 68.9 \% \text { improved vs. } 4.8 \% \text { for placebo; } \\
\text { incomplete emptying } 68.8 \% \text { improved vs. } 7.7 \% \text { for } \\
\text { placebo }\end{array}$ \\
\hline Braeckman & {$[41]$} & 1994 & Prostaserene $\mathrm{CO}_{2}$ & 305 & 3 & $\begin{array}{c}\Delta \text { IPSS }-6.6(34.7 \%) ; \Delta \text { QoL }-1.54(41.6 \%) ; \Delta \mathrm{Q}_{\max } \\
+2.41(26.4 \%)\end{array}$ \\
\hline Carraro & [17] & 1996 & $\begin{array}{l}\text { Permixon } \\
\text { Hexane }\end{array}$ & 467 & 6 & $\begin{array}{l}\text { Permixon vs. finasteride; } \downarrow \text { IPSS by } 37 \% \text { vs. } 39 \% \text {; } \\
\uparrow Q \text { QL by } 38 \% \text { vs. } 41 \% \text {; } Q_{\max }+2.7 \text { vs. }+3.2 \mathrm{~mL} / \mathrm{s}\end{array}$ \\
\hline Braeckman & [45] & $1997 a$ & Prostaserene $\mathrm{CO}_{2}$ & 67 & 12 & IPSS -6.8, QoL $-1.5, \mathrm{Q}_{\max }+2.6 \mathrm{~mL} / \mathrm{s}$ \\
\hline Braeckman & {$[44]$} & $1997 b$ & Prostaserene $\mathrm{CO}_{2}$ & 125 & 3 & $\begin{array}{c}\Delta \text { "IPSS" }-4.0(51.3 \%) \text { (scoring system per SBS); } \Delta \\
\mathrm{Q}_{\max }+3.1(29.8 \%) \text { vs. placebo "IPSS" }-1.7(25.4 \%) \\
\text { and } \Delta \mathrm{Q}_{\max }+1.1(10 \%)\end{array}$ \\
\hline Bauer & [59] & 1999 & Talso $\mathrm{CO}_{2}$ & 101 & 6 & IPSS $\downarrow 37 \%$ at study end; no hard numbers, only \% \\
\hline Gerber & {$[60]$} & 2001 & $\begin{array}{l}\text { Solaray } \\
\text { Ethanol }\end{array}$ & 39 & 6 & $\begin{array}{c}\text { IPSS }-4.4(26 \%) \text { vs. }-2.2(14 \%) ; \mathrm{QoL}-0.7(21 \%) \text { vs. } \\
-0.3(10 \%) ; \mathrm{Q}_{\max }+1.0 \text { vs. }+1.4\end{array}$ \\
\hline Debruyne & [19] & 2002 & $\begin{array}{l}\text { Permixon } \\
\text { Hexane }\end{array}$ & 350 & 12 & $\begin{array}{l}\text { Permixon vs. tamsulosin with IPSS improvement } \\
\text { of } 28 \% \text { vs. } 29 \% ; \mathrm{Q}_{\max } \uparrow 1.8 \text { vs. } 1.9 \mathrm{~mL} / \mathrm{s}\end{array}$ \\
\hline Willetts & [61] & 2003 & Proseren $\mathrm{CO}_{2}$ & 46 & 3 & $\begin{array}{c}\Delta \text { QoL }-0.49(13 \%) \text { vs. placebo }-0.69(17 \%) ; \Delta \\
\text { Qmax no significant difference, IPSS calculated from } \\
\text { graphs }-1.1(7.8 \%) \text { vs. }-3.9(21.8 \%) \text { for placebo; } \\
\text { negative study }\end{array}$ \\
\hline Debruyne & [18] & 2004 & $\begin{array}{l}\text { Permixon } \\
\text { Hexane }\end{array}$ & 124 & 12 & $\begin{array}{c}\text { Permixon vs. tamsulosin: } \Delta \text { IPSS }-7.8(35 \%) \text { vs. } \\
-5.8(25 \%) ; \Delta \text { QoL }-1.2(29 \%) \text { vs. }-0.9(23 \%) ; \Delta \\
\text { Qmax }+1.2(11 \%) \text { vs. }+1.7(17 \%)\end{array}$ \\
\hline Bent & [14] & 2006 & Indena USA $\mathrm{CO}_{2}$ & 112 & 12 & $\begin{array}{c}\text { Serenoa vs. placebo: } \Delta \text { IPSS }-0.68(4.3 \%) \text { vs. }-0.72 \\
(4.8 \%) ; \Delta Q_{\max }+0.42(3.6 \%) \text { vs. }-0.01(-0.09 \%) ; \\
\text { negative study }\end{array}$ \\
\hline Hizli & [22] & 2007 & $\begin{array}{l}\text { Prostagood }^{\circledR} \\
\text { Ethanol * }^{*}\end{array}$ & 20 & 6 & $\begin{array}{l}\text { Serenoa vs. tamsulosin vs. Serenoa plus } \\
\text { tamsulosin; } \Delta \mathrm{IPSS}-6.1(34 \%) \text { vs. }-4.6(28 \%) \text { vs. } \\
-4.9(31 \%) ; \Delta \mathrm{QoL}-2.6(62 \%) \text { vs. }-2.1(60 \%) \text { vs. } \\
-2.2(63 \%) ; \Delta \mathrm{Q}_{\max }+3.2(34 \%) \text { vs. }+3.7(35 \%) \text { vs. } \\
+4.2(42 \%) ; \text { no benefit with combination }\end{array}$ \\
\hline Barry & [15] & 2011 & $\begin{array}{l}\text { Prosta Urgenin } \\
\text { Ethanol }\end{array}$ & 164 & 18 & $\begin{array}{c}\text { S. repens vs. placebo: } \Delta \text { AUA-SI }-2.20(15 \%) \text { vs. } \\
-2.99(20 \%) ; \Delta \text { QoL }-0.34(10.6 \%) \text { vs. }-0.49 \\
(15.2 \%) ; \Delta Q_{\max }-0.18(-1.2 \%) \text { vs. }-0.79(-5.3 \%) ; \\
\text { negative study }\end{array}$ \\
\hline
\end{tabular}

Note: ${ }^{a}$ Number of patients at study end or as reported. ${ }^{*}$ Prostagood $^{\circledR}$ is the brand name in Turkey for the EESr product Prostagutt uno, also known as WS 1473. $\Delta$, mean change; $\downarrow$, decreased; $\uparrow$, increased; - , negative change; \#, number; + , positive change; AUA-SI, American Urological Association Symptom Index; $\mathrm{CO}_{2}$, carbon dioxide; IPSS, International Prostate Symptom Score; mL/s, milliliters per second; mos, months; QoL, quality of life; $\mathrm{Q}_{\max }$, peak urinary flow (mL/s); Ref., reference citation; vs., versus.

Of the evaluable studies, 12 of the 15 showed efficacy for Serenoa repens. Only three studies-Willetts 2003, Bent 2006, and Barry 2011-are negative studies insofar as disclosing no benefit from Serenoa repens $[14,15,61]$. The product used in the Willetts study was Proseren ${ }^{\circledR}$, manufactured by Blackmores in Australia. Per communication with their website support team, this was a $1600 \mathrm{mg}$ Serenoa capsule derived from a $10: 1 \mathrm{CO}_{2}$ ex- 
traction process with a dose equivalent to $320 \mathrm{mg} /$ day. This product has not been used in another LUTS/BPH study. The Serenoa repens used in the Bent study and manufactured by Indena also has not been used in another published LUTS study. The Barry study selected an ethanolic extract of Serenoa repens (EESr) called Prosta Urgenin Uno ${ }^{\circledR}$ (Rottapharm/Madaus), with results indicating it to be no better than placebo using the AUA-SI as the objective endpoint [15]. In an earlier large 3-month intervention study by Derakhshani et al. [47] but not discussed by Barry et al., Prosta Urgenin Uno was used in 1047 patients from 357 urologic practices. At study end, Derakhshani reported an overall mean change in IPSS of -7.4 points, representing a $40 \%$ improvement; a QoL change of -1.61 , representing a $45.9 \%$ improvement; and a $Q_{\max }$ increase after 3 months of $+3.7 \mathrm{~mL} / \mathrm{s}$ for a 30.8\% improvement. This striking difference in clinical outcomes with Prosta Urgenin Uno between Derakhshani 1997 and Barry 2011 has never been addressed by any author, until this current report.

Only half of the studies considered by Cochrane 2012 used consistent symptom scoring (i.e., IPSS, AUA-SI). Therefore, clinical data from the Cochrane meta-analysis drew from inconsistent symptom assessment methodology. Moreover, Cochrane 2012 included some studies involving saw palmetto products of inconsistent and/or indeterminant quality. The authors of the updated Cochrane 2012 meta-analysis acknowledged that their conclusions might not be generalizable to products containing a standardized extract of $S$. repens with an established chemical composition [25,26]. A total of 6 of the $35(17 \%)$ citations in Cochrane 2012, upon detailed review (SBS), indicated negative findings. The three evaluable studies were discussed above. The other three studies with a lack of benefit from the LSESr arm were non-evaluable because they used Serenoa in combination with additional herbal products (Englemann, Lopatkin) $[62,63]$ or the study was only of six weeks duration (Löbelenz) [63].

As to the extraction process used, five evaluable studies in Cochrane 2012 used the standardized hexanic lipidosterolic extract of Serenoa repens with the brand name of Permixon ${ }^{\circledR}$ (Pierre Fabre Medicament S.A.), and all showed efficacy (Table 2) $[17,19,30,58,64]$. There were also non-evaluable studies in Cochrane 2012 that had used a standardized hexanic lipidosterolic extract of Serenoa repens versus placebo or comparator. Of these six studies, four had $<20$ patients (Boccafoschi, Emili, Mandressi, Tasca) [65-68] and four had a study duration of $<2$ months (Champault, Descotes, Emili, Mandressi) $[64,66,67,69]$. Emili and Mandressi had both $<20$ patients and $<2$ months study duration. Table 3 presents an assessment of the clinical findings in these six studies. As an aside, all six studies, although non-evaluable per criteria, reported a significant benefit in clinical outcome for Serenoa repens in LUTS versus placebo or comparator. The mean outcomes across these six studies are: $\mathrm{Q}_{\max }+3.4 \mathrm{~mL} / \mathrm{s}$ (five studies), decreased nocturia by $55 \%$ (three studies), and decreased urgency by $65 \%$ (two studies).

Table 3. Efficacy of the hexane extract of S. repens vs. placebo. Six of 20 non-evaluable studies in Cochrane 2012 used a standardized hexanic lipidosterolic extract and reported clinical improvement in symptoms vs. placebo.

\begin{tabular}{|c|c|c|c|c|c|}
\hline Senior Author & Year & $\begin{array}{l}\text { Ref. } \\
\text { (\#) }\end{array}$ & $\begin{array}{c}\text { Serenoa } \\
\text { Patients (\#) a }\end{array}$ & $\begin{array}{l}\text { Study Duration } \\
\text { (mos) }\end{array}$ & Key Results for Serenoa vs. Placebo or Comparator \\
\hline Boccafoschi & 1983 & {$[65]$} & 11 & 2 & $\mathrm{Q}_{\max }+4.2(42 \%)$ vs. placebo $+2.1(20.6 \%)$ \\
\hline Emili & 1983 & [66] & 15 & 1 & $\mathrm{Q}_{\max }+3.56(34.5 \%)$ vs. placebo $+0.20(2.2 \%)$ \\
\hline Mandressi & 1983 & [67] & 19 & 1 & $\begin{array}{c}\text { Serenoa vs. Pygeum vs. placebo; } \downarrow \text { urgency } 70 \% \text { vs. } 62 \% \text { vs. } \\
24 \% ; \downarrow \text { frequency } 30 \% \text { vs. } 22 \% \text { vs. } 10 \% ; \downarrow \text { nocturia } 42 \% \text { vs. } 38 \% \\
\text { vs. }-4 \%\end{array}$ \\
\hline Champault & 1984 & [69] & 50 & 1 & $\begin{array}{c}\mathrm{Q}_{\max }+2.7(50.5 \%) \text { vs. placebo }+0.25(5 \%) ; \text { nocturia }-1.53(49 \%) \\
\text { vs. placebo }-0.48(15 \%)\end{array}$ \\
\hline Tasca & 1985 & {$[68]$} & 14 & 2 & $\begin{array}{c}\text { Qmax }+3.3(25.6 \%) \text { vs. placebo }-0.6(-5 \%) \text {; nocturia } 74.3 \% \text { vs. } \\
38.7 \% \text {; urgency } 60 \% \text { vs. } 20 \% \text {; weak stream } 50 \% \text { vs. } 16.6 \%\end{array}$ \\
\hline Descotes & 1995 & [64] & 82 & 1 & $\mathrm{Q}_{\max }+3.4(28.9 \%)$ vs. placebo $+1.1(8.9 \%)$ \\
\hline \multicolumn{5}{|c|}{ Average Changes in Qmax, Nocturia and Urgency } & $\mathrm{Q}_{\max }+3.4 ; \downarrow \downarrow$ nocturia $55 \% ; \downarrow \downarrow$ urgency $65 \%$ \\
\hline
\end{tabular}

Note: ${ }^{a}$ Number of patients at study end or as reported. $\downarrow$, decreased; - , negative change; \#, number; +, positive change; mos, months; $\mathrm{Q}_{\text {max }}$, peak urinary flow (mL/s); Ref., reference citation; vs., versus. 
A critique of 2012 Cochrane, published in 2015 by Bachmann, detailed many of the previously mentioned issues [70]. It also mentioned that some studies in Cochrane 2012 used doses lower than $320 \mathrm{mg} /$ day. The lack of consistent criteria for evaluability is a significant criticism in this meta-analysis, and it is even more the case when considering the number of evaluable studies that were never assessed by Cochrane 2012. Bachmann's major criticism was the lack of logic in conclusions reached by Cochrane 2012 when contrasting the efficacy of Serenoa repens with established comparison prescription products such as finasteride, tamsulosin, and gestonorone caproate. Paraphrasing Bachmann, if Serenoa repens has the same effect as placebo, as well as the same effect as the comparison products, then the three established prescription drugs are also ineffective and logically should be considered no better than placebo [70].

Additional thoughts can be offered for Cochrane 2012. A decline in IPSS by $\geq 3$ points has been considered to be an indicator of efficacy of any agent in the treatment of LUTS [71-73]. Eight studies involving Serenoa repens in Cochrane 2012 had clinically meaningful IPSS improvement with an average drop of -6.14 , and a range from -4.4 to -9 , as shown in Table 2. Some of these LSESr preparations were combination products involving either phytonutrients and vitamins or $\alpha$-blockers and were studies tagged as non-evaluable by our established criteria and not included in our results. Why the authors of Cochrane 2012 selected so many studies with such clear-cut deficiencies is difficult to understand. Nonetheless, despite such obvious laxity involving study selection in Cochrane 2012, the reported results within Cochrane 2012 do not justify the official stated conclusions.

\subsection{The American Urological Association Guidelines (AUAG 2014)}

The American Urological Association guidelines (AUAG) for the management of BPH were revised in 2014 [28]. The guideline authors considered literature from 1 January 1999 to 28 February 2008. Studies on Serenoa repens that were non-English full-text studies or that had an English abstract but not the full paper were excluded. The AUAG 2014 key findings can be summarized as: "At this time, the available data do not suggest that saw palmetto has a clinically meaningful effect on LUTS secondary to BPH. Further clinical trials are in progress and the results of these studies will elucidate the potential value of saw palmetto extracts in the management of patients with BPH." The two references cited by McVary et al. were Bent 2006 and Shi 2008 [14,74]. The Shi paper used a combination product containing lyophilized prostate, Serenoa extract, zinc, flower pollen, Pygeum, pumpkin seed, and more [74]. Certainly, the Shi study is not evaluable and should not have been cited. The Bent 2006 publication is one of the two major articles relating to the lack of efficacy of Serenoa repens in treating LUTS [14]. As mentioned previously, the Bent trial used a $\mathrm{CO}_{2}$ Serenoa extract manufactured by Indena. Although no peer-reviewed studies using the Indena product to confirm or refute the Bent results have been published to date, the Bent study is routinely cited concerning the lack of efficacy of LSESr for reducing LUTS.

Statements in AUAG 2014 about the use of dietary supplements are worthy of further comment: " . . most patients who use dietary supplements self-medicate with these products and often do not inform their physicians about this use". This statement reflects how uncomfortable most patients feel about reporting their supplement use to their physicians. The reality is that most physicians disparage any non-prescription use, and from the patient's point of view, physicians in general regard supplement use as taboo and not open for discussion. If the physician asks the patient about what dietary supplement(s) he may be using, then this information is freely exchanged between the patient and the physician and/or his staff. "Furthermore, the quality and purity of these OTC supplements are not rigorously monitored, adding further uncertainty about the value and safety of these products," is indeed a major problem in countries such as the US. Regulation of supplement quality and/or use is not nearly as strict as in other parts of the world. In Germany, for example, the hexane extraction product Permixon is a prescription item.

AUAG 2014 references Cochrane 2012 in saying: "Serenoa repens was not more effective than placebo for the treatment of urinary symptoms consistent with BPH." However, this 
again refers to the publication of Bent 2006 [14] and also to reports by Barry 2011 [15] and Willetts 2003 [61]. Willetts, like Bent, used a product that has never been used in any other peer-reviewed publication. Willetts compared a $\mathrm{CO}_{2}$ extraction product in fifty patients versus 50 receiving a placebo in a study period of 3 months. Note that in ESCOP and EMA, such study durations were criticized as being too short for accurate assessment. Willetts 2003 reported no significant differences in $Q_{\max }$ or QoL between Serenoa repens extract and placebo. IPSS data, extracted from a graph (SBS), indicated the IPSS for the Serenoa extract group went from a baseline of $\approx 14.1$ to 13 , while paradoxically, that of placebo went from $\approx 17.9$ to 14 , a drop of 3.9 points. Improvement in the IPSS of $\geq 3$ points is cited as a criterion of product efficacy [71-73,75-77]. Of additional interest is that $Q_{\max }$ improved for both the Serenoa extract and placebo groups by $2.35 \mathrm{~mL} / \mathrm{s}$. Details on the profile of the Blackmores product could not be confirmed. Thus, Barry 2011 remains the most valid negative study that impugns the value of LSESr in LUTS [15]. This will be discussed in more detail later in the context of the many evaluable studies showing favorable responses with LSESr that were not considered by the EMA and the AUA.

AUAG 2014 was significantly critical of the studies by Debruyne 2002 and Hizli 2007 [19,22]. "One of the two trials that compared saw palmetto with tamsulosin in 704 men reported a decline in AUA-SI scores of 4.4 points in both treatment groups [Debruyne 2002]; the other also reported no significant difference in the change in symptom scores among 40 randomized men when comparing LSESr to tamsulosin [Hizli 2007]." AUAG 2014 concluded: "In the two comparisons of saw palmetto with the alpha-blocker tamsulosin, there was no significant difference in changes in LUTS-related QoL between the treatment arms." In addition, "The active-controlled studies comparing saw palmetto with tamsulosin also found no significant difference in urinary flow rates at closeout." Such statements could be misconstrued that Serenoa lacked efficacy, but instead, the emphasis should have been that tamsulosin was no better than Serenoa repens. In other words, the two were equivalent in efficacy insofar as IPSS, QoL, and $\mathrm{Q}_{\max }$ endpoints. If we look at the two referenced studies $[19,22]$ and extract the data related to the endpoints above, it is clear that there is significant value in the use of Serenoa repens in LUTS, as seen in Table 4 . Note also that this criticism of AUAG 2014 is essentially identical to that made by Bachmann [70] of Cochrane 2012.

Table 4. Debruyne 2002 and Hizli 2007 clinical evaluation of LSESr vs. tamsulosin (Flomax ${ }^{\circledR}$ ) at study end. These two clinical trials were cited by AUA 2014 as broadly indicative of the lack of value of "saw palmetto" to ameliorate LUTS, despite essentially identical results with tamsulosin.

\begin{tabular}{|c|c|c|c|c|c|c|c|c|c|}
\hline \multirow{2}{*}{$\begin{array}{l}\text { Senior Author } \\
\text { Year, Ref. (\#) }\end{array}$} & \multirow{2}{*}{$\begin{array}{c}\text { Study Duration } \\
\text { (mos) }\end{array}$} & \multirow{2}{*}{ Study Arm } & \multirow{2}{*}{ Patients (\#) ${ }^{a}$} & \multicolumn{2}{|c|}{ IPSS } & \multicolumn{2}{|c|}{ QoL } & \multicolumn{2}{|c|}{$\overline{Q_{\max }}$} \\
\hline & & & & $\Delta$ & $\%$ & $\Delta$ & $\%$ & $\mathrm{~mL} / \mathrm{s}$ & $\%$ \\
\hline \multirow{2}{*}{ Debruyne 2002 [19] } & \multirow{2}{*}{12} & LSESr & 350 & -4.5 & $29 \%$ & $\overline{\mathrm{NR}}$ & NR & +1.8 & $17 \%$ \\
\hline & & Tam & 354 & -4.4 & $29 \%$ & NR & NR & +1.8 & $16 \%$ \\
\hline \multirow{2}{*}{ Hizli 2007 [22] } & \multirow[b]{2}{*}{6} & LSESr & 20 & -6.1 & $34 \%$ & -2.6 & $62 \%$ & +3.2 & $34 \%$ \\
\hline & & Tam & 20 & -4.6 & $28 \%$ & -2.1 & $60 \%$ & +3.7 & $35 \%$ \\
\hline
\end{tabular}

a Number of patients at study end. $\Delta$, mean change; -, negative change; \#, number; $\%$, percentage change; +, positive change; AUA American Urological Association; IPSS, International Prostate Symptom Score; LSESr, lipidosterolic extract of Serenoa repens; LUTS, lower urinary tract symptoms; $\mathrm{mL} / \mathrm{s}$, milliliters per second; NR, not reported; mos, months; QoL, quality of life; $\mathrm{Q}_{\max }$, peak urinary flow (mL/s); Ref., reference citation; Tam, tamsulosin.

For all reports, the clinical value of Serenoa is with the lipidosterolic extract of Serenoa repens (LSESr), and this ought to be routinely distinguished from the unacceptable naming of the study product as "saw palmetto" or "Serenoa repens". Such distinction must be emphasized in all scientific publications and presentations to the lay public. Saw palmetto, Serenoa, Serenoa repens, and S. repens, do not equate, per se, with the lipidosterolic extract of Serenoa repens (LSESr), or specifically with a hexane, ethanol, or carbon dioxide lipidosterolic extraction product at the accepted daily dose of 320 milligrams per day and meeting the fatty acid profile standards of the EMA and US Pharmacopeia.

In Table 4, the IPSS improvement with Serenoa repens was comparable with that of tamsulosin (Debruyne 2002, Hizli 2007). The improvements as a percentage in IPSS, QoL, 
and $Q_{\max }$ are essentially equivalent. Debruyne 2002 involved eleven European countries enrolling 811 patients with a baseline IPSS of $\geq 11$ [19]. This double-blinded, randomized study also included a 4-week run-in phase to exclude patients who were non-compliant in taking the placebo. At study end, the per-protocol patient numbers were 350 in the LSESr group (Permixon) and 354 in the tamsulosin group. If the findings quoted above represent a placebo effect, then tamsulosin must also be considered a placebo. As stated in Debruyne 2002, "In each group, more than $80 \%$ of the patients exhibited a decrease in IPSS. A decrease in IPSS by at least 3 points was observed in two-thirds (67\%) of the patients and by at least 5 points in half of them (49\%). The greatest improvement in IPSS total score was observed in those patients with the greatest severity of disease. For the severe patients (with a baseline IPSS > 19; $n=94$ ), the mean changes from baseline were greater in the Permixon group than in the tamsulosin group (8.0 and 6.8, respectively). As for side effects, ejaculation disorders were significantly more frequent with tamsulosin $(15$, or $4.2 \%)$ than with Permixon $(2$, or $0.6 \% ; p=0.001)$ [19]".

Hizli 2007 randomized patients into three groups of 20 patients: LSESr monotherapy, tamsulosin monotherapy, and LSESr combined with tamsulosin [22]. No additive or synergistic effect was seen in the combination arm. QoL in Hizli showed similar improvements, with changes from baseline to six months of 4.2 to 1.6 (62\% improvement) and 3.5 to 1.4 (60\% improvement) for LSESr and tamsulosin, respectively. If any conclusion were to be stated by AUAG 2014, it should have been that LSESr monotherapy, using the commercial product Prostagood (licensed to Abdi Ibrahim Pharmaceuticals in Turkey), was comparable with tamsulosin monotherapy in lessening LUTS, using the endpoints of IPSS, QoL, and $Q_{\max }$. AUAG 2014 further criticizes the same two studies for not using the BPH Impact Index (BPHII or BII). "The BPHII was not assessed in either of the other two placebocontrolled studies nor in the studies comparing saw palmetto with an alpha-blocker." This criticism could be directed at virtually every study involving conventional medical therapy for LUTS since almost all studies do not include BPHII data. Moreover, QoL (aka IPSS-BQ) has been shown to be a reliable index correlating with the severity of LUTS, and also highly correlated with the bother question in the BPHII [78].

AUAG 2014 discussed the Carraro study, which compared the standardized hexanic LSESr, Permixon, versus finasteride for 6 months [17]. Results of that study showed Permixon improved IPSS by 37\%, improved QoL by 38\%, and improved $Q_{\max }$ by $+2.7 \mathrm{~mL} / \mathrm{s}$ $(25 \%$ ) versus $39 \%, 41 \%$, and $+3.2 \mathrm{~mL} / \mathrm{s}$ for finasteride (Table 2). Nonetheless, AUAG 2014 only mentions Carraro with "saw palmetto does not affect serum PSA (prostate-specific antigen) levels." Lastly, AUAG 2014 remarked that there were no significant differences in adverse events between the two arms of all Serenoa versus placebo-controlled trials, and that "only" the Bent 2006 study conducted thorough lab testing for potential toxicity [14]. The topic of safety will be discussed in detail in Part II, but scores of peer-reviewed clinical publications and meta-analyses on LSESr have consistently reported on the safety and tolerability of LSESr. A thorough evaluation of adverse effects is therefore not unique to Bent 2006 [12,42,45,64,79,80]. What appears commonplace in orthodox medicine are criticisms routinely directed to natural products but less so when referencing prescription drugs. I would aver that double standards have no place in medicine. Additionally, there may be a conflict of interest, noting that two panel members of AUAG 2014 were also authors in the Bent 2006 and Barry 2011 studies.

\subsection{The European Medicines Agency Monograph (EMA 2014)}

The EMA 85-page monograph reported by Laekeman in 2014 [12] based its conclusions mainly on the review of 15 clinical articles cited by ESCOP 2003 [27] and 20 clinical articles cited by Cochrane 2012 [25,26]. Seven publications are unique to EMA 2014 and appear to have been obtained from a PubMed search. Of these seven papers, three were nonevaluable per prior criteria established for this review. The complete EMA report presents information on the use of Serenoa repens in various countries in the EU, basic science information on possible mechanisms of action of Serenoa, and studies involving analyses 
of efficacy and toxicity. EMA 2014 found that only "one well conducted controlled clinical trial with the supercritical $\mathrm{CO}_{2}$ extract has been published" (Braeckman et al. 1997a) [45], but the provided information is not sufficient to support its use as "a well-established medicinal product" (i.e., recognized efficacy and acceptable safety). EMA 2014 further affirms, "The requirement for 30 years of experience on the market is not fulfilled for the supercritical $\mathrm{CO}_{2}$ extract". A similar conclusion is reached concerning the ethanolic extraction products of Serenoa repens. "Although ethanolic extracts are widely used in EU member states, the clinical data available are limited." EMA 2014 concluded that "only the hexane extract of the fruit of Serenoa repens is considered to be supported by sufficient evidence to grant a well-established use as a medicinal product with recognised efficacy and acceptable safety".

EMA 2014 is challenging in its mixed messages since it also states, "The use of the ethanolic extracts is considered plausible on the basis of clinical studies with related extracts and the long-standing use and experience. The benefit-risk balance of commercialized ethanolic extracts is positive and a traditional use can be granted." Moreover, further stated by the monograph authors, "Other double-blind, randomised, placebo-controlled studies have been carried out with extracts that were not sufficiently documented and (not) registered in EU member states. Despite the fact that the studies were generally well conducted, the results cannot be used to elaborate the monograph." It therefore appears that if a commercial product is not registered by the EU, it is rejected. Many readers may misconstrue such a report as a valid scientific analysis of the body of clinical literature. Of additional concern in EMA 2014 are the assessor's comments, which are essentially a "verdict" as to the acceptability of a study. However, a blank area is present where the assessor's identity would be shown. The monograph is replete with criticisms about various studies, yet the individual's identity who has made these remarks is not provided. If transparency and possible conflicts of interest are important in evaluations of scientific merit, then this principle should apply to all.

\subsection{What Can Be Learned from ESCOP 2003, Cochrane 2012, AUAG 2014, and EMA 2014?}

These four authoritative reports have influenced the perception of many urologists concerning the efficacy of LSESr versus LUTS. Figure 3 depicts the evaluable versus nonevaluable assessment of the 69 citations that relate to LSESr efficacy in LUTS that are discussed in ESCOP 2003, Cochrane 2012, and EMA2014. Since there were no unique citations presented in AUAG, these 69 published studies represent the evidence considered by these four authoritative bodies. Of these 69 studies, approximately half (36 studies, 52\%) were considered evaluable for an assessment of efficacy. AUAG 2014 did cite six citations that were considered to be evaluable, and all six were cited by at least two of the three other authoritative publications $[14,17,19,22,60,61]$. As stated earlier, the Carraro 1996 reference was cited concerning LSESr as not having an effect on PSA levels but lacked any discussion of clinical endpoints affecting LSESr versus LUTS [17].

Using the detailed notes compiled during the critical review and analysis (SBS), a summary of the body of literature (69 published studies) considered across ESCOP 2003, Cochrane 2012, AUAG 2014, and the EMA 2014 was created. Table 5 notes which studies were considered by each authoritative body, and includes data on Serenoa product/extract method, study patient numbers, and study duration for 56 of the 69 cited papers. The evaluable studies ( 36 of 69 or $52 \%$ ) are indicated with the senior author's name bolded. The remaining non-evaluable studies (33 of 69 or $48 \%$ ), show the senior author in normal font. A total of 14 of 36 trials were unique to either ESCOP, Cochrane, or EMA, whereas 22 studies were cited in two or more of these reports. AUAG 2014 did not contain any unique publications. When comparing ESCOP, Cochrane, AUAG, and EMA, there were $58 \%, 43 \%, 54 \%$, and $58 \%$ evaluable papers, respectively. In other words, approximately $50 \%$ of the studies considered by these authoritative publications failed to meet the criteria for evaluability in our investigation of the utility of Serenoa in the treatment of LUTS. 


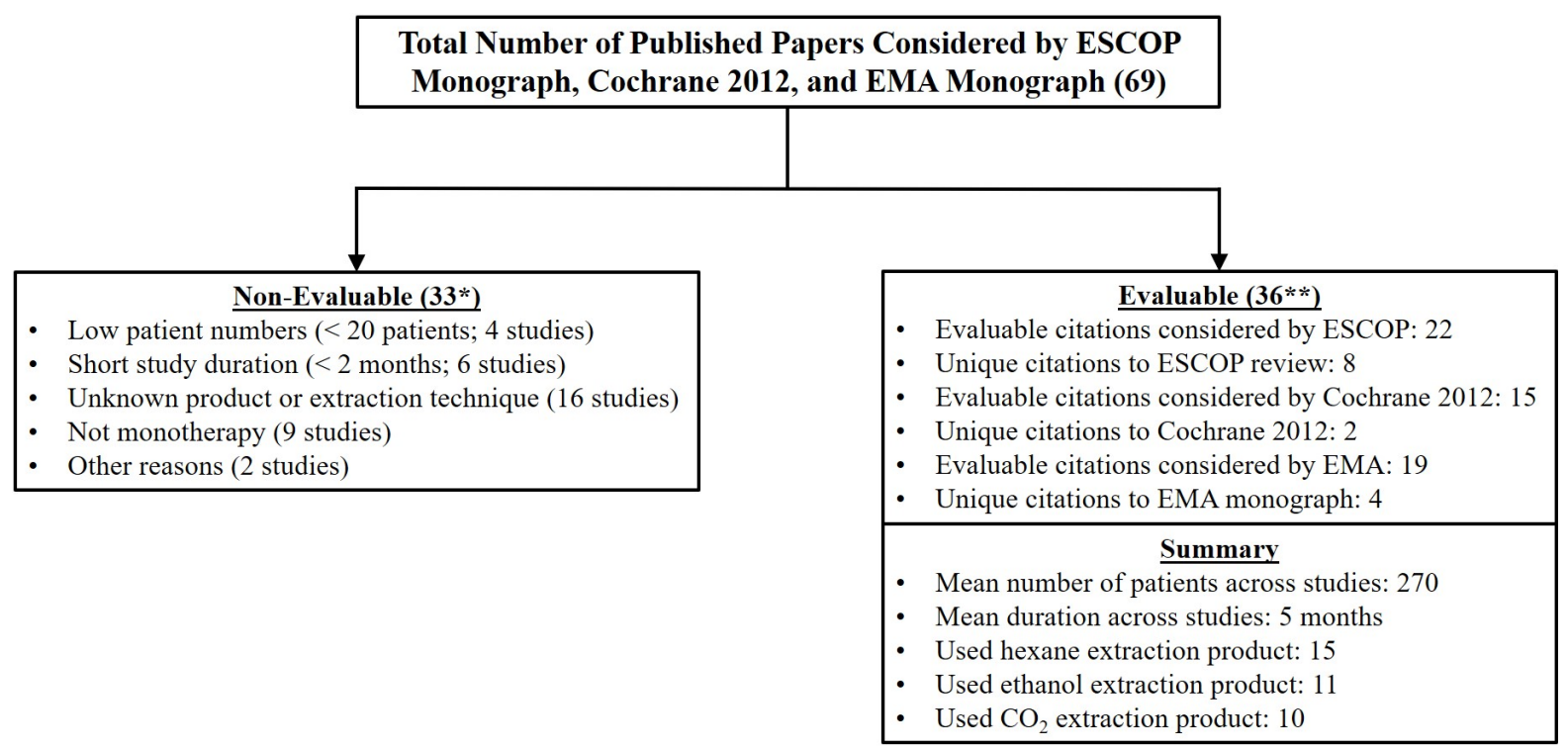

Figure 3. Categorization of 69 evaluable citations in ESCOP 2003, Cochrane 2012, and EMA 2014. * Studies could have more than one reason for exclusion. ${ }^{* *}$ Of the 36 evaluable citations, 22 were considered by ESCOP (61\%), 15 by Cochrane (42\%), and 19 by EMA (53\%). There were eight studies unique to ESCOP, two studies unique to Cochrane. EMA cited four studies not found in either of the other two reviews. $\mathrm{CO}_{2}$, carbon dioxide; EMA, European Medicines Agency; ESCOP, European Scientific Cooperative on Phytotherapy.

Table 5. Summary of all citations from ESCOP, Cochrane 2012, AUAG, and EMA.

\begin{tabular}{|c|c|c|c|c|c|c|c|c|c|c|}
\hline $\begin{array}{l}\text { Senior } \\
\text { Author }\end{array}$ & Year & $\begin{array}{c}\text { Evaluable } \\
\text { y or } n\end{array}$ & Product & Extraction & $\begin{array}{l}\text { Serenoa } \\
\text { Pts (\#) }^{a}\end{array}$ & $\begin{array}{c}\text { Study } \\
\text { Duration } \\
\text { (mos) }\end{array}$ & ESCOP & Cochrane & AUAG & EMA \\
\hline Bach + & 1996 & $\mathrm{y}$ & Strogen S & $\mathrm{CO}_{2}$ & 315 & 36 & $*$ & & & \\
\hline Bauer $\ddagger$ & 1999 & $\mathrm{y}$ & Talso uno & $\mathrm{CO}_{2}$ & 101 & 6 & & $*$ & & \\
\hline Bent + & 2006 & $\mathrm{y}$ & Indena USA & $\mathrm{CO}_{2}$ & 112 & 12 & & + & + & + \\
\hline Braeckman † & 1994 & $\mathrm{y}$ & Prostaserene & $\mathrm{CO}_{2}$ & 505 & 3 & + & + & & + \\
\hline Braeckman1 1 & 1997 & $\mathrm{y}$ & Prostaserene & $\mathrm{CO}_{2}$ & 67 & 12 & + & + & & + \\
\hline Braeckman $2+$ & 1997 & $\mathrm{y}$ & Prostaserene & $\mathrm{CO}_{2}$ & 125 & 3 & & + & & + \\
\hline Fabricius $\ddagger$ & 1993 & $\mathrm{y}$ & Talso & $\mathrm{CO}_{2}$ & 176 & 6 & + & & & + \\
\hline Kondas $†$ & 1996 & $\mathrm{y}$ & Strogen forte & $\mathrm{CO}_{2}$ & 38 & 6 & $*$ & & & \\
\hline Mattei $\ddagger$ & 1988 & $\mathrm{y}$ & Talso & $\mathrm{CO}_{2}$ & 20 & 3 & + & + & & + \\
\hline Romics † & 1993 & $\mathrm{y}$ & Strogen forte & $\mathrm{CO}_{2}$ & 31 & 12 & $*$ & & & \\
\hline Vahlensieck $\ddagger$ & 1993 & $\mathrm{y}$ & Talso uno & $\mathrm{CO}_{2}$ & 1334 & 4 & + & & & + \\
\hline Vahlensieck $\ddagger$ & 1993 & $\mathrm{y}$ & Talso uno & $\mathrm{CO}_{2}$ & 312 & 3 & + & & & + \\
\hline Willetts † & 2003 & $\mathrm{y}$ & Proseren & $\mathrm{CO}_{2}$ & 46 & 3 & & + & + & + \\
\hline Barry + & 2011 & $\mathrm{y}$ & Prosta Urgenin & ethanol & 151 & 18 & & + & & + \\
\hline Derakhshani $\ddagger$ & 1997 & $\mathrm{y}$ & Prosta Urgenin & ethanol & 1047 & 3 & * & & & \\
\hline Eickenberg $\ddagger$ & 1997 & $\mathrm{y}$ & Sita & ethanol & 6967 & 6 & $*$ & & & \\
\hline Gerber + & 1998 & $\mathrm{y}$ & Solaray & ethanol & 46 & 6 & $*$ & & & \\
\hline Gerber + & 2001 & $\mathrm{y}$ & Solaray & ethanol & 39 & 6 & & + & + & + \\
\hline Hizli + & 2007 & $\mathrm{y}$ & Prostagood & ethanol & 20 & 6 & & + & + & + \\
\hline Redecker $\ddagger$ & 1998 & $\mathrm{y}$ & Prostagutt & ethanol & 50 & 3 & $*$ & & & \\
\hline Ziegler $\ddagger$ & 1998 & $\mathrm{y}$ & Prostagutt & ethanol & 109 & 3 & $*$ & & & \\
\hline Authie $\ddagger$ & 1987 & $\mathrm{y}$ & Permixon & hexane & 500 & 3 & * & & & \\
\hline Carraro ${ }^{\dagger}$ & 1996 & $\mathrm{y}$ & Permixon & hexane & 467 & 6 & + & + & + & + \\
\hline
\end{tabular}


Table 5. Cont.

\begin{tabular}{|c|c|c|c|c|c|c|c|c|c|c|}
\hline $\begin{array}{l}\text { Senior } \\
\text { Author }\end{array}$ & Year & $\begin{array}{c}\text { Evaluable } \\
\text { y or } n\end{array}$ & Product & Extraction & $\begin{array}{l}\text { Serenoa } \\
\text { Pts (\#) }\end{array}$ & $\begin{array}{l}\text { Study } \\
\text { Duration } \\
\text { (mos) }\end{array}$ & ESCOP & Cochrane & AUAG & EMA \\
\hline Cirillo-Marucco $\ddagger$ & 1983 & $\mathrm{y}$ & Permixon & hexane & 47 & 4 & * & & & \\
\hline Cukier $\ddagger$ & 1985 & $\mathrm{y}$ & Permixon & hexane & 73 & 2 & + & + & & + \\
\hline Dathe $\ddagger$ & 1991 & $\mathrm{y}$ & Permixon & hexane & 49 & 6 & + & & & + \\
\hline Debruyne † & 2002 & $\mathrm{y}$ & Permixon & hexane & 350 & 12 & & + & + & + \\
\hline Debruyne $\dagger$ & 2004 & $\mathrm{y}$ & Permixon & hexane & 124 & 12 & & + & & + \\
\hline $\begin{array}{l}\text { Giannakopoulos } \\
+\end{array}$ & 2002 & $\mathrm{y}$ & Permixon & hexane & 100 & 6 & & & & * \\
\hline Giulianelli † & 2012 & $\mathrm{y}$ & Permixon & hexane & 591 & 6 & & & & $*$ \\
\hline Ollé Carreras ‡ & 1987 & $\mathrm{y}$ & "hexane" & hexane & 40 & 2 & $*$ & & & \\
\hline Orfei $\ddagger$ & 1988 & $\mathrm{y}$ & Permixon & hexane & 30 & 3 & $*$ & & & \\
\hline Pannunzio $\ddagger$ & 1986 & $\mathrm{y}$ & Permixon & hexane & 30 & 2 & & $*$ & & \\
\hline Pescatore $\ddagger$ & 1986 & $\mathrm{y}$ & Permixon & hexane & 30 & 3 & * & & & \\
\hline Pytel † & 2002 & $\mathrm{y}$ & Permixon & hexane & 116 & 24 & & & & $*$ \\
\hline Stepanov + & 1999 & $\mathrm{y}$ & Permixon & hexane & 92 & 3 & & & & * \\
\hline Kaplan † & 2004 & $\mathrm{n}$ & nos & - & & & & & & $*$ \\
\hline Marks † & 2000 & $\mathrm{n}$ & Nutrilite Blend & - & 20 & 6 & & + & + & \\
\hline Mohanty + & 1999 & $\mathrm{n}$ & nos & - & 36 & 2 & & * & & \\
\hline Preuss + & 2001 & $\mathrm{n}$ & $\begin{array}{c}\text { Herbs } \\
\text { Vitamins }\end{array}$ & - & & & & + & + & \\
\hline Roveda $\ddagger$ & 1994 & $\mathrm{n}$ & $\begin{array}{l}\text { Serpens } \\
\text { nos }\end{array}$ & - & 30 & 1 & & * & & \\
\hline Schneider $\ddagger$ & 1994 & $\mathrm{n}$ & nos & - & & & + & & & + \\
\hline Breu $\ddagger$ & 1992 & $\mathrm{n}$ & Talso uno & $\mathrm{CO}_{2}$ & & & + & & & + \\
\hline Hagenlocher $\ddagger$ & 1993 & $\mathrm{n}$ & SG $291 \lambda$ & $\mathrm{CO}_{2}$ & & & * & & & \\
\hline Shit & 2008 & $\mathrm{n}$ & Prostataplex & $\mathrm{CO}_{2}$ & 46 & 3 & & + & + & + \\
\hline Carbin + & 1990 & $\mathrm{n}$ & $\begin{array}{l}\text { Sabal serrulata }+ \\
\text { Curbicin }\end{array}$ & combo & 26 & 3 & & * & & \\
\hline Engelmann $†$ & 2006 & $\mathrm{n}$ & $\begin{array}{c}\text { Prostagutt forte }+ \\
\text { Urtica }\end{array}$ & combo & 56 & 15 & & + & + & \\
\hline Lopatkin † & 2005 & $\mathrm{n}$ & $\begin{array}{l}\text { Prostagutt + } \\
\text { Urtica }\end{array}$ & combo & 129 & 6 & & + & + & \\
\hline Sökeland $\ddagger$ & 1997 & $\mathrm{n}$ & $\begin{array}{l}\text { Prostagutt + } \\
\text { Urtica }\end{array}$ & combo & 245 & 12 & & * & & \\
\hline Gabric $\ddagger$ & 1987 & $\mathrm{n}$ & Prostagutt & ethanol & 15 & 1.5 & & * & & \\
\hline Helfand $t$ & 2012 & $\mathrm{n}$ & Prosta Urgenin & ethanol & & & & & & * \\
\hline Koch $\ddagger$ & 1994 & $\mathrm{n}$ & Prostagutt & ethanol & & & * & & & \\
\hline Koch $\ddagger$ & 1995 & $\mathrm{n}$ & Prostagutt & ethanol & & & $*$ & & & \\
\hline Löbelenz $\ddagger$ & 1992 & $\mathrm{n}$ & Sabal & ethanol & 30 & 1.5 & . & + & & + \\
\hline Metzker $\ddagger$ & 1996 & $\mathrm{n}$ & $\begin{array}{l}\text { Prostagutt + } \\
\text { Urtica }\end{array}$ & ethanol & 37 & 12 & & * & & \\
\hline Boccafoschi $\ddagger$ & 1983 & $\mathrm{n}$ & Permixon & hexane & 11 & 2 & + & + & & + \\
\hline Champault $\ddagger$ & 1984 & $\mathrm{n}$ & Permixon & hexane & 50 & 1 & + & + & & + \\
\hline Descotes $\boldsymbol{t}$ & 1995 & $\mathrm{n}$ & Permixon & hexane & 82 & 1 & + & + & & + \\
\hline Emili $\ddagger$ & 1983 & $\mathrm{n}$ & Permixon & hexane & 15 & 1 & + & + & & + \\
\hline Glémain $\ddagger$ & 2002 & $\mathrm{n}$ & Permixon & hexane & 159 & 12 & & + & & + \\
\hline Grasso t & 1995 & $\mathrm{n}$ & Permixon & hexane & & & + & & & + \\
\hline Mancuso $\ddagger$ & 1986 & $\mathrm{n}$ & Permixon & hexane & & & $*$ & & & \\
\hline Mandressi $\ddagger$ & 1983 & $\mathrm{n}$ & Permixon & hexane & 19 & 1 & & * & & \\
\hline Martorana $\ddagger$ & 1986 & $\mathrm{n}$ & Permixon & hexane & & & * & & & \\
\hline Paoletti $\ddagger$ & 1986 & $\mathrm{n}$ & Permixon & hexane & 18 & 2 & $*$ & & & \\
\hline Pytel $\ddagger \Psi$ & 2004 & $\mathrm{n}$ & Permixon & hexane & & & & & & $*$ \\
\hline
\end{tabular}


Table 5. Cont.

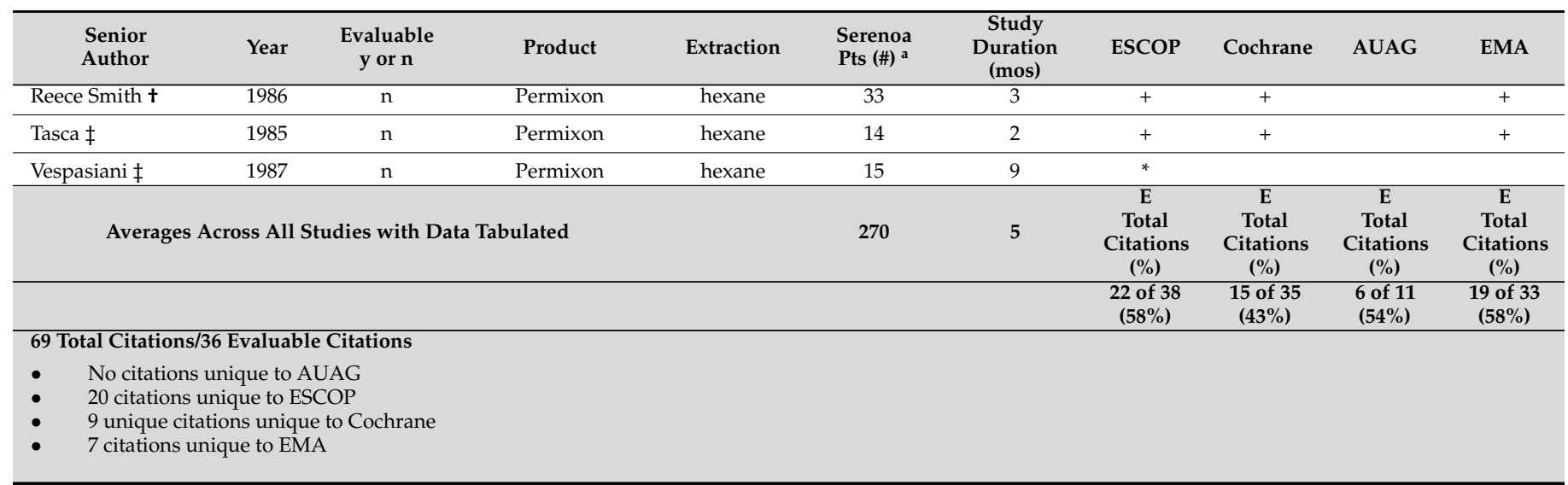

Of the 69 citations across the reports, 33 citations (48\%) were not evaluable for determinations on the efficacy of LSESr for LUTS. Only one citation, Carraro [17], was considered by all four reports. Of the evaluable studies, 15 used a standardized hexane extract, 8 used an ethanol extract, and 13 used a supercritical carbon dioxide extract of Serenoa repens. ${ }^{a}$ Number of patients at study end, or as reported. † Publications in English; $\ddagger$ non-English publications; $\Psi$ Pytel 2004 identical to Pytel 2002; * Unique to that report; + Cited by that report; AUAG, American Urological Association Guidelines; $\mathrm{CO}_{2}$, carbon dioxide; EMA, European Medicines Agency; ESCOP, European Scientific Cooperative on Phytotherapy; LSESr, lipidosterolic extract of Serenoa repens; LUTS, lower urinary tract symptoms; y, yes; n, no; Pts, patients; mos, months; \#, number; E, evaluable.

A total of 38 non-English-language papers were cited by ESCOP, Cochrane 2012, and the EMA authors, with the majority in German (19) or Italian (13). A total of $52 \%$ of the German language papers were evaluable, but only $31 \%$ of the Italian language papers were evaluable due to small patient numbers ( $<20$ patients in the Serenoa arm) and short study duration ( $<2$ months). Of the 31 English-language papers considered by ESCOP, Cochrane, and EMA, 61\% were evaluable, including the 3 negative studies by Willetts 2003, Bent 2006, and Barry 2011 [14,15,61]. In considering the extraction products used in those remaining 36 evaluable studies in ESCOP, Cochrane 2012, and EMA, 15 studies (42\%) used a hexane-extracted product, 8 (22\%) used an ethanol-extracted product, and $13(36 \%)$ used a $\mathrm{CO}_{2}$ extraction product.

For the 56 studies that have information summarized in Table 5 for product, patient number, and study duration, the mean number of patients across the studies was 270 , and the mean study duration was 5 months, indicating a robust set of clinical trials of Serenoa repens for efficacy in treating LUTS. If a larger percentage of evaluable studies and non-English-language papers had been considered by the four authoritative bodies, the efficacy of LSESr for LUTS would have been affirmed.

\section{What Information Is Not Controversial?}

The suggested target population for supplement use in LUTS involves men in the watchful waiting phase with mild-to-moderate symptoms who are not yet "particularly bothered [81]". During this early treatment period, and for that matter during any phase of the treatment of LUTS, it is crucial to select a Serenoa extract product that can achieve an optimal outcome insofar as a decrease in symptoms and a lack of progression and/or resolution of the underlying pathophysiology that has caused LUTS. Crushed dried saw palmetto berry powder is not relevant to LUTS nor is it comparable with a lipidosterolic extract, but unfortunately, this has not been recognized by most urologists. Definitions for a standardized Serenoa extract product are suggested by the US Pharmacopeia [13] and EMA [12] and would have a lipid profile with a minimum of $80 \%$ total fatty acids, would have a specific ratio of fatty acids and be rich in free fatty acids, and would have a minimum amount of phytosterols and fatty alcohols. Unfortunately, the specific makeup of Serenoa and the percentage of components that determine efficacy in treating LUTS have not been ascertained. The hexanoic extract product, Permixon, which does meet the above standard, has shown established benefit in LUTS. This will be detailed later in Parts II and III of this review, which will discuss the lipidosterolic products vs. the three 
extraction methods that have efficacy in the treatment of LUTS. As for dosing, efficacy has been established at the recommended dose of $320 \mathrm{mg} /$ day of the lipidosterolic extract, and higher doses do not offer further benefit $[21,36]$. It is not established if a lower dose can be efficacious. Additionally, the safety of LSESr has been repeatedly cited in the literature and also is not controversial. The technical role of extraction in regard to outcome in LUTS will be discussed in Part II of this review and has been a topic of debate [12].

With these fundamental principles (target population and standardized extract) in mind, it is clear that the clinical evaluation of LSESr has been negatively impacted by the following: (1) variability in the composition and quality of LSESr; (2) a primary focus on LUTS progression being related to prostate enlargement rather than the more clinically relevant outcome of storage (irritative) and flow (obstructive) symptoms, and; (3) a need for long-term studies of LSESr focused on delay in progression and perhaps resolution of LUTS, and, in the best-case scenario, inhibition of the histologic development and clinical progression of $\mathrm{BPH}$. Therefore, it is of great importance to critically evaluate the scientific evidence related to the use of LSESr for LUTS, with a particular focus on (1) standardized extraction products of known quality, (2) standardized dosing, (3) efficacy using measurable endpoints such as IPSS, QoL, and $\mathrm{Q}_{\max }$, (4) durability of response, (5) safety, and 6) the ability to delay the progression of LUTS that relates to the pathobiology of LUTS associated with BPH and/or inflammation.

\section{Conclusions in Part I}

Part I of this series of three articles focused on re-exploring the use of the herbal product Serenoa repens in the treatment of male LUTS. I have described what LUTS is, why it is an increasingly important concern in the changing demographics of our world, and some basic information valuable to understanding clinical studies of LUTS. Most importantly, I have addressed the four major reports or meta-analyses of Serenoa use in LUTS and elaborated with detailed findings on issues that have negatively influenced the use of standardized Serenoa products in the clinical context of male LUTS. These findings were brought to the forefront because of a more complete analysis of the English-language peer-reviewed articles and also because of the far broader scope of this analysis that resulted from including translated non-English language publications with an in-depth analysis of their data. Part I, therefore, lays the foundation for Parts II and III of this global analysis in which important derivative findings relating to LUTS and LSESr will be presented.

Funding: The author received a consulting fee for researching and compiling this review. The manuscript fees were paid by Valensa International.

Institutional Review Board Statement: Not applicable.

Informed Consent Statement: Not applicable.

Data Availability Statement: Not applicable.

Conflicts of Interest: The author serves as a paid consultant for Valensa International. He receives a consulting fee for services to Life Extension.

Ethical Approval/Patient Consent: This is a review of the literature and did not require an ethical board approval.

\section{References}

1. Lee, C.L.; Kuo, H.C. Pathophysiology of benign prostate enlargement and lower urinary tract symptoms: Current concepts. Ci Ji Yi Xue Za Zhi 2017, 29, 79-83. [CrossRef] [PubMed]

2. Song, Q.; Abrams, P.; Sun, Y. Beyond prostate, beyond surgery and beyond urology: The "3Bs" of managing non-neurogenic male lower urinary tract symptoms. Asian J. Urol. 2019, 6, 169-173. [CrossRef] [PubMed]

3. Barry, M.J.; Fowler, F.J., Jr.; O'Leary, M.P.; Bruskewitz, R.C.; Holtgrewe, H.L.; Mebust, W.K.; Cockett, A.T. The American Urological Association symptom index for benign prostatic hyperplasia. The Measurement Committee of the American Urological Association. J. Urol. 1992, 148, 1549-1557. [CrossRef] 
4. Cockett, A.T.; Aso, Y.; Denis, L.; Khoury, S.; Barry, M.; Carlton, C.E.; Coffey, D.; Fitzpatrick, J.; Griffiths, K.; Hald, T.; et al. World Health Organization Consensus Committee recommendations concerning the diagnosis of BPH. Prog. Urol. 1991, 1, $957-972$.

5. Abrams, P.; Cardozo, L.; Fall, M.; Griffiths, D.; Rosier, P.; Ulmsten, U.; Van Kerrebroeck, P.; Victor, A.; Wein, A.; Standardisation Sub-Committee of the International Continence Society. The standardisation of terminology in lower urinary tract function: Report from the standardisation sub-committee of the International Continence Society. Urology 2003, 61, 37-49. [CrossRef]

6. Chapple, C.R.; Wein, A.J.; Abrams, P.; Dmochowski, R.R.; Giuliano, F.; Kaplan, S.A.; McVary, K.T.; Roehrborn, C.G. Lower urinary tract symptoms revisited: A broader clinical perspective. Eur. Urol. 2008, 54, 563-569. [CrossRef] [PubMed]

7. Yalla, S.V.; Sullivan, M.P.; Lecamwasam, H.S.; DuBeau, C.E.; Vickers, M.A.; Cravalho, E.G. Correlation of American Urological Association symptom index with obstructive and nonobstructive prostatism. J. Urol. 1995, 153, 674-679. [CrossRef]

8. McVary, K.T.; Peterson, A.; Donatucci, C.F.; Baygani, S.; Henneges, C.; Clouth, J.; Wong, D.; Oelke, M. Use of Structural Equation Modeling to Demonstrate the Differential Impact of Storage and Voiding Lower Urinary Tract Symptoms on Symptom Bother and Quality of Life during Treatment for Lower Urinary Tract Symptoms Associated with Benign Prostatic Hyperplasia. J. Urol. 2016, 196, 824-830. [CrossRef] [PubMed]

9. McVary, K.T.; Roehrborn, C.G.; Avins, A.L.; Barry, M.J.; Bruskewitz, R.C.; Donnell, R.F.; Foster, H.E., Jr.; Gonzalez, C.M.; Kaplan, S.A.; Penson, D.F.; et al. Update on AUA guideline on the management of benign prostatic hyperplasia. J. Urol. 2011, 185, 1793-1803. [CrossRef] [PubMed]

10. Oelke, M.; Bachmann, A.; Descazeaud, A.; Emberton, M.; Gravas, S.; Michel, M.C.; N’Dow, J.; Nordling, J.; de la Rosette, J.J.; European Association of Urology. EAU guidelines on the treatment and follow-up of non-neurogenic male lower urinary tract symptoms including benign prostatic obstruction. Eur. Urol. 2013, 64, 118-140. [CrossRef] [PubMed]

11. Lazarou, J.; Pomeranz, B.H.; Corey, P.N. Incidence of adverse drug reactions in hospitalized patients: A meta-analysis of prospective studies. JAMA 1998, 279, 1200-1205. [CrossRef]

12. Laekeman, G.; Vlietinck, A. Assessment Report on Serenoa Repens (W. Bartram) Small, Fructus. Available online: http:/ www. ema.europa.eu/docs/en_GB/document_library/Herbal_-_HMPC_assessment_report/2014/12/WC500179593.pdf (accessed on 14 November 2020).

13. USP. Saw Palmetto Extract. Available online: https://online.uspnf.com/uspnf/document/1_GUID-53E14A4F-6F17-4CF1-852CC6547F5A79DB_5_en-US (accessed on 1 November 2020).

14. Bent, S.; Kane, C.; Shinohara, K.; Neuhaus, J.; Hudes, E.S.; Goldberg, H.; Avins, A.L. Saw palmetto for benign prostatic hyperplasia. N. Engl. J. Med. 2006, 354, 557-566. [CrossRef]

15. Barry, M.J.; Meleth, S.; Lee, J.Y.; Kreder, K.J.; Avins, A.L.; Nickel, J.C.; Roehrborn, C.G.; Crawford, E.D.; Foster, H.E., Jr.; Kaplan, S.A.; et al. Effect of increasing doses of saw palmetto extract on lower urinary tract symptoms: A randomized trial. JAMA 2011, 306, 1344-1351. [CrossRef] [PubMed]

16. Al-Shukri, S.H.; Deschaseaux, P.; Kuzmin, I.V.; Amdiy, R.R. Early urodynamic effects of the lipido-sterolic extract of Serenoa repens (Permixon $(\mathrm{R}))$ in patients with lower urinary tract symptoms due to benign prostatic hyperplasia. Prostate Cancer Prostatic Dis. 2000, 3, 195-199. [CrossRef] [PubMed]

17. Carraro, J.C.; Raynaud, J.P.; Koch, G.; Chisholm, G.D.; Di Silverio, F.; Teillac, P.; Da Silva, F.C.; Cauquil, J.; Chopin, D.K.; Hamdy, F.C.; et al. Comparison of phytotherapy (Permixon) with finasteride in the treatment of benign prostate hyperplasia: A randomized international study of 1,098 patients. Prostate 1996, 29, 231-240. [CrossRef]

18. Debruyne, F.; Boyle, P.; Calais Da Silva, F.; Gillenwater, J.G.; Hamdy, F.C.; Perrin, P.; Teillac, P.; Vela-Navarrete, R.; Raynaud, J.P.; Schulman, C.C. Evaluation of the clinical benefit of permixon and tamsulosin in severe BPH patients-PERMAL study subset analysis. Eur. Urol. 2004, 45, 773-779. [CrossRef] [PubMed]

19. Debruyne, F.; Koch, G.; Boyle, P.; Da Silva, F.C.; Gillenwater, J.G.; Hamdy, F.C.; Perrin, P.; Teillac, P.; Vela-Navarrete, R.; Raynaud, J.P. Comparison of a phytotherapeutic agent (Permixon) with an alpha-blocker (Tamsulosin) in the treatment of benign prostatic hyperplasia: A 1-year randomized international study. Eur. Urol. 2002, 41, 497-506. [CrossRef]

20. Djavan, B.; Fong, Y.K.; Chaudry, A.; Reissigl, A.; Anagnostou, T.; Bagheri, F.; Waldert, M.; Fajkovic, H.; Marihart, S.; Harik, M.; et al. Progression delay in men with mild symptoms of bladder outlet obstruction: A comparative study of phytotherapy and watchful waiting. World J. Urol. 2005, 23, 253-256. [CrossRef] [PubMed]

21. Giannakopoulos, X.; Baltogiannis, D.; Giannakis, D.; Tasos, A.; Sofikitis, N.; Charalabopoulos, K.; Evangelou, A. The lipidosterolic extract of Serenoa repens in the treatment of benign prostatic hyperplasia: A comparison of two dosage regimens. Adv. Ther. 2002, 19, 285-296. [CrossRef] [PubMed]

22. Hizli, F.; Uygur, M.C. A prospective study of the efficacy of Serenoa repens, tamsulosin, and Serenoa repens plus tamsulosin treatment for patients with benign prostate hyperplasia. Int. Urol. Nephrol. 2007, 39, 879-886. [CrossRef]

23. Pytel, Y.A.; Vinarov, A.; Lopatkin, N.; Sivkov, A.; Gorilovsky, L.; Raynaud, J.P. Long-term clinical and biologic effects of the lipidosterolic extract of Serenoa repens in patients with symptomatic benign prostatic hyperplasia. Adv. Ther. 2002, 19, 297-306. [CrossRef] [PubMed]

24. Stepanov, V.N.; Siniakova, L.A.; Sarrazin, B.; Raynaud, J.P. Efficacy and tolerability of the lipidosterolic extract of Serenoa repens (Permixon) in benign prostatic hyperplasia: A double-blind comparison of two dosage regimens. Adv. Ther. 1999, 16, $231-241$. [PubMed]

25. MacDonald, R.; Tacklind, J.W.; Rutks, I.; Wilt, T.J. Serenoa repens monotherapy for benign prostatic hyperplasia (BPH): An updated Cochrane systematic review. BJU Int. 2012, 109, 1756-1761. [CrossRef] 
26. Tacklind, J.; Macdonald, R.; Rutks, I.; Stanke, J.U.; Wilt, T.J. Serenoa repens for benign prostatic hyperplasia. Cochrane Database Syst. Rev. 2012, 12, CD001423. [CrossRef]

27. Serenoae Repentis Fructus (Sabal Fructus) Saw Palmetto Fruit. ESCOP Monographs, 2nd ed.; George Thieme Verlag: New York, NY, USA, 2003.

28. McVary, K.T.; Roehrborn, C.; Avins, A.L.; Barry, M.J.; Bruskewitz, R.C.; Donnell, R.F.; Foster, J.; Harris, E.; Gonzalez, C.M.; Kaplan, S.A.; et al. Management of Benign Prostatic Hyperplasia. Published 2010; Reviewed and Validity Confirmed 2014. Available online: https:/ / www.auanet.org/guidelines/benign-prostatic-hyperplasia-(bph)-guideline/benign-prostatic-hyperplasia-(20 10-reviewed-and-validity-confirmed-2014) (accessed on 4 May 2020).

29. Cirillo-Marucco, E.; Pagliarulo, A.; Tritto, G.; Piccinno, A.; Di Rienzo, U. Serenoa repens extract (Permixon $\left.{ }^{\circledR}\right)$ in the early treatment of prostatic hypertrophy. Urol. J. 1983, 50, 1269-1277. [CrossRef]

30. Cukier; Ducassou; Guillou, L. Permixon versus placebo. CR Ther. Pharmacol. Clin. 1985, 4, 15-21. (In French)

31. Pescatore, D.; Calvi, P.; Michelotti, P. Urodynamic assessment of treatment in patients with prostatic adenoma with Serenoa repens extract. Urol. J. 1986, 53, 894-897. [CrossRef]

32. Authie, D.; Cauquil, J. Assessment of the effectiveness of Permixon* in daily practice multicentric study. CR Ther. Pharmacol. Clin. 1987, 5, 3-13. (In French)

33. Ollé Carreras, J. Our experience with hexane extract from Serenoa repens in the treatment of benign prostatic hypertrophy. Arch. Esp. Urol. 1987, 40, 310-313. (In Spanish) [PubMed]

34. Orfei, S.; Grumelli, B.; Galetti, G. Clinical and uroflowimetric evaluation of Permixon ${ }^{\circledR}$ in geriatrics. Urol. J. 1988, 55, 373-381. [CrossRef]

35. Mattei, F.M.; Capone, M.; Acconcia, A. Medicamentous therapy of benign prostatic hyperplasia with an extract of the sagebrush. TW Urol. Nephrol. 1990, 2, 346-350. (In German)

36. Dathe, G.; Schmid, H. Phytotherapy for benign prostatic hyperplasia (BPH) with Extractum Serenoa repens (Permixon). Urologe. Ausgabe B 1991, 31, 223-330. (In German)

37. Fabricius, P.G.; Vahlensieck jr., W. Therapy for benign prostatic hyperplasia: Sabal fruit extract: One dose is enough! Therapiewoche 1993, 43, 1616-1620. (In German)

38. Romics, I.; Schmitz, H.; Frang, D. Experience in treating benign prostatic hypertrophy with Sabal serrulata for one year. Int. Urol. Nephrol. 1993, 25, 565-569. [PubMed]

39. Vahlensieck, W., Jr.; Volp, A.; Lubos, W.; Kuntze, M. Benign prostatic hyperplasia-treatment with sabal fruit extract. A treatment study of 1334 patients. Fortschr. Med. 1993, 111, 323-326. (In German)

40. Vahlensieck, W.; Völp, A.; Kuntze, M.; Lubos, W. Changes in micturition in patients with benign prostatic hyperplasia under sabal fruit treatment. Urologe. Ausg. B 1993, 33, 380-383. (In German)

41. Braeckman, J. The extract of Serenoa repens in the treatment of benign prostatic hyperplasia: A multicenter open study. Curr. Ther. Res. 1994, 55, 776-785. [CrossRef]

42. Bach, D.; Ebeling, L. Long-term drug treatment of benign prostatic hyperplasia-Results of a prospective 3-year multicenter study using Sabal extract IDS 89. Phytomedicine 1996, 3, 105-111. [CrossRef]

43. Kondas, J.; Philipp, V.; Dioszeghy, G. Sabal serrulata extract (Strogen forte) in the treatment of symptomatic benign prostatic hyperplasia. Int. Urol. Nephrol. 1996, 28, 767-772. [CrossRef]

44. Braeckman, J.; Denis, L.; De Leval, J.; Keuppens, F.; Cornet, A.; De Bruyne, R.; De Smedt, E.; Pacco, J.; Timmermans, L.; Van Vliet, P. A double-blind, placebo-controlled study of the plant extract Serenoa repens in the treatment of benign hyperplasia of the prostate. Eur. J. Clin. Res. 1997, 9, 247-259.

45. Braeckman, J.; Bruhwyler, J.; Vanderkerckhove, K.; Géczy, J. Efficacy and safety of the extract of Serenoa repens in the treatment of benign prostatic hyperplasia: Therapeutic equivalence between twice and once daily dosage forms. Phytother. Res. 1997, 11, 558-563. [CrossRef]

46. Gerber, G.S.; Zagaja, G.P.; Bales, G.T.; Chodak, G.W.; Contreras, B.A. Saw palmetto (Serenoa repens) in men with lower urinary tract symptoms: Effects on urodynamic parameters and voiding symptoms. Urology 1998, 51, 1003-1007. [CrossRef]

47. Derakhshani, P.; Geerke, H.; Böhnert, K.J.; Engelmann, U. Influencing the international prostate symptom score during therapy with saw palmetto fruit extract with a single daily dose. Der. Urol. B 1997, 37, 384-391. [CrossRef]

48. Eickenberg, H.U. Treatment of benign prostatic hyperplasia with a lipophilic extract from saw palmetto fruits (Sita). Der. Urol. B 1997, 37, 130-133. [CrossRef]

49. Redecker, K.D.; Funk, P. Sabal-Extrakt WS 1473 bei benigner Prostatahyperplasie. Extr. Urol. 1998, $21,23-25$.

50. Ziegler, H.; Holscher, U. Efficacy of saw palmetto fruit special extract WS 1473 in patients with Alken stage I-II benign prostatic hyperplasia-open multicentre study. Jatros. Urol. 1998, 14, 34-43. (In German)

51. Wilt, T.J.; Ishani, A.; Rutks, I.; MacDonald, R. Phytotherapy for benign prostatic hyperplasia. Public Health Nutr. 2000,3 , 459-472. [CrossRef] [PubMed]

52. Wilt, T.; Ishani, A.; Mac Donald, R. Serenoa repens for benign prostatic hyperplasia. Cochrane Database Syst. Rev. 2002, CD001423.

53. Tacklind, J.; MacDonald, R.; Rutks, I.; Wilt, T.J. Serenoa repens for benign prostatic hyperplasia. Cochrane Database Syst. Rev. 2009, CD001423. [CrossRef]

54. Sökeland, J.; Albrecht, J. Combined Sabal and Urtica extract vs finasteride in BPH (Alken stage I-II). Der Urol. 1997, 36, 327-333. [CrossRef] 
55. Sokeland, J. Combined sabal and urtica extract compared with finasteride in men with benign prostatic hyperplasia: Analysis of prostate volume and therapeutic outcome. BJU Int. 2000, 86, 439-442. [CrossRef]

56. Mohanty, N.; Jha, R.; Dutt, C. Randomized double-blind controlled clinical trial of serenoa repens versus placebo in the management of patients with symptomatic grade I to grade II benign prostatic hyperplasia (BPH). Indian J. Urol. 1999, 15, 26-31.

57. Reece Smith, H.; Memon, A.; Smart, C.J.; Dewbury, K. The value of permixon in benign prostatic hypertrophy. Br. J. Urol. 1986, 58, 36-40. [CrossRef] [PubMed]

58. Pannunzio, E.; D'Ascenzo, R.; Giardinetti, F.; Civili, P.; Persichelli, E. Serenoa Repens vs. Gestonorone Caproato in the Treatment of Benign Prostatic Hypertrophy: Randomized Study. Urol. J. 1986, 53, 696-705. [CrossRef]

59. Bauer, H.W.; Casarosa, C.; Cosci, M.; Fratta, M.; Blessmann, G. Saw palmetto fruit extract for treatment of benign prostatic hyperplasia. Results of a placebo-controlled double-blind study. MMW Fortschr. Med. 1999, 141, 62. (In German)

60. Gerber, G.S.; Kuznetsov, D.; Johnson, B.C.; Burstein, J.D. Randomized, double-blind, placebo-controlled trial of saw palmetto in men with lower urinary tract symptoms. Urology 2001, 58, 960-964. [CrossRef]

61. Willetts, K.E.; Clements, M.S.; Champion, S.; Ehsman, S.; Eden, J.A. Serenoa repens extract for benign prostate hyperplasia: A randomized controlled trial. BJU Int. 2003, 92, 267-270. [CrossRef]

62. Engelmann, U.; Walther, C.; Bondarenko, B.; Funk, P.; Schlafke, S. Efficacy and safety of a combination of sabal and urtica extract in lower urinary tract symptoms. A randomized, double-blind study versus tamsulosin. Arzneimittelforschung 2006, 56, 222-229. [PubMed]

63. Lobelenz, J. Extractum Sabal fructus for benign prostatic hyperplasia (BPH). Clinical trial in stages I and II. Therapeutikon 1992, 6, 34-37. (In German)

64. Descotes, J.L.; Rambeaud, J.J.; Deschaseaux, P.; Faure, G. Placebo-Controlled Evaluation of the Efficacy and.Tolerability of Permixon®in Benign Prostatic Hyperplasia after Exclusion of Placebo Responders. Clin. Drug Investig. 1995, 9, $291-297$. [CrossRef]

65. Boccafoschi, C.; Annoscia, S. Comparison of Serenoa repens extract and placebo in controlled clinical trial in patients with prostatic adenomatosis. Urologiia 1983, 50, 1-14. (In Italian)

66. Emili, E.; Lo Cigno, M.; Petrone, U. Clinical results on a new drug in prostate hypertrophy therapy (Permixon). Nefrologia Chirurgica 1983, 50, 1042-1048. (In Italian) [CrossRef]

67. Mandressi, A.; Tarallo, U.; Maggioni, A.; Tombolini, P.; Rocco, F.; Quadraccia, S. Medical treatment of benign prostatic hyperplasia: Efficacy of the extract of Serenoa repens (Permixon) compared to that of the extract of Pygeum africanum and a placebo. Urologia 1983, 50, 752-758. (In Italian) [CrossRef]

68. Tasca, A.; Barulli, M.; Cavazzana, A.; Zattoni, F.; Artibani, W.; Pagano, F. Treatment of obstructive symptomatology caused by prostatic adenoma with an extract of Serenoa repens. Double-blind clinical test v. placebo. Minerva Urol. Nefrol. 1985, 37, 87-91. (In Italian)

69. Champault, G.; Patel, J.C.; Bonnard, A.M. A double-blind trial of an extract of the plant Serenoa repens in benign prostatic hyperplasia. Br. J. Clin. Pharmacol. 1984, 18, 461-462. [CrossRef] [PubMed]

70. Bachmann, C. Serenoa repens in benign prostatic hyperplasia. Schweiz. Z. Ganzheitsmed./Swiss J. Integr. Med. 2015, 27, 202-206. (In German) [CrossRef]

71. Barry, M.J.; Williford, W.O.; Chang, Y.; Machi, M.; Jones, K.M.; Walker-Corkery, E.; Lepor, H. Benign prostatic hyperplasia specific health status measures in clinical research: How much change in the American Urological Association symptom index and the benign prostatic hyperplasia impact index is perceptible to patients? J. Urol. 1995, 154, 1770-1774. [CrossRef]

72. Boeri, L.; Capogrosso, P.; Ventimiglia, E.; Cazzaniga, W.; Pederzoli, F.; Moretti, D.; Deho, F.; Montanari, E.; Montorsi, F.; Salonia, A. Clinically Meaningful Improvements in LUTS/BPH Severity in Men Treated with Silodosin Plus Hexanic Extract of Serenoa Repens or Silodosin Alone. Sci. Rep. 2017, 7, 15179. [CrossRef]

73. Nickel, J.C.; Brock, G.B.; Herschorn, S.; Dickson, R.; Henneges, C.; Viktrup, L. Proportion of tadalafil-treated patients with clinically meaningful improvement in lower urinary tract symptoms associated with benign prostatic hyperplasia-Integrated data from 1499 study participants. BJU Int. 2015, 115, 815-821. [CrossRef]

74. Shi, R.; Xie, Q.; Gang, X.; Lun, J.; Cheng, L.; Pantuck, A.; Rao, J. Effect of saw palmetto soft gel capsule on lower urinary tract symptoms associated with benign prostatic hyperplasia: A randomized trial in Shanghai, China. J. Urol. 2008, 179, 610-615. [CrossRef]

75. Abrams, P.; Schulman, C.C.; Vaage, S. Tamsulosin, a selective alpha 1c-adrenoceptor antagonist: A randomized, controlled trial in patients with benign prostatic 'obstruction' (symptomatic BPH). The European Tamsulosin Study Group. Br. J. Urol. 1995, 76, 325-336. [CrossRef]

76. Barry, M.J.; Cantor, A.; Roehrborn, C.G.; Group, C.S. Relationships among participant international prostate symptom score, benign prostatic hyperplasia impact index changes and global ratings of change in a trial of phytotherapy in men with lower urinary tract symptoms. J. Urol. 2013, 189, 987-992. [CrossRef]

77. McConnell, J.D.; Bruskewitz, R.; Walsh, P.; Andriole, G.; Lieber, M.; Holtgrewe, H.L.; Albertsen, P.; Roehrborn, C.G.; Nickel, J.C.; Wang, D.Z.; et al. The effect of finasteride on the risk of acute urinary retention and the need for surgical treatment among men with benign prostatic hyperplasia. Finasteride Long-Term Efficacy and Safety Study Group. N. Engl. J. Med. 1998, 338, 557-563. [CrossRef] 
78. O'Leary, M.P. Validity of the "bother score" in the evaluation and treatment of symptomatic benign prostatic hyperplasia. Rev. Urol. 2005, 7, 1-10. [PubMed]

79. Agbabiaka, T.B.; Pittler, M.H.; Wider, B.; Ernst, E. Serenoa repens (saw palmetto): A systematic review of adverse events. Drug Saf. 2009, 32, 637-647. [CrossRef] [PubMed]

80. Novara, G.; Giannarini, G.; Alcaraz, A.; Cozar-Olmo, J.M.; Descazeaud, A.; Montorsi, F.; Ficarra, V. Efficacy and Safety of Hexanic Lipidosterolic Extract of Serenoa repens (Permixon) in the Treatment of Lower Urinary Tract Symptoms Due to Benign Prostatic Hyperplasia: Systematic Review and Meta-analysis of Randomized Controlled Trials. Eur. Urol. Focus 2016, 2, 553-561. [CrossRef] [PubMed]

81. Roehrborn, C.G. Male lower urinary tract symptoms (LUTS) and benign prostatic hyperplasia (BPH). Med. Clin. 2011, 95, 87-100. [CrossRef] [PubMed] 